BMC

Genomics

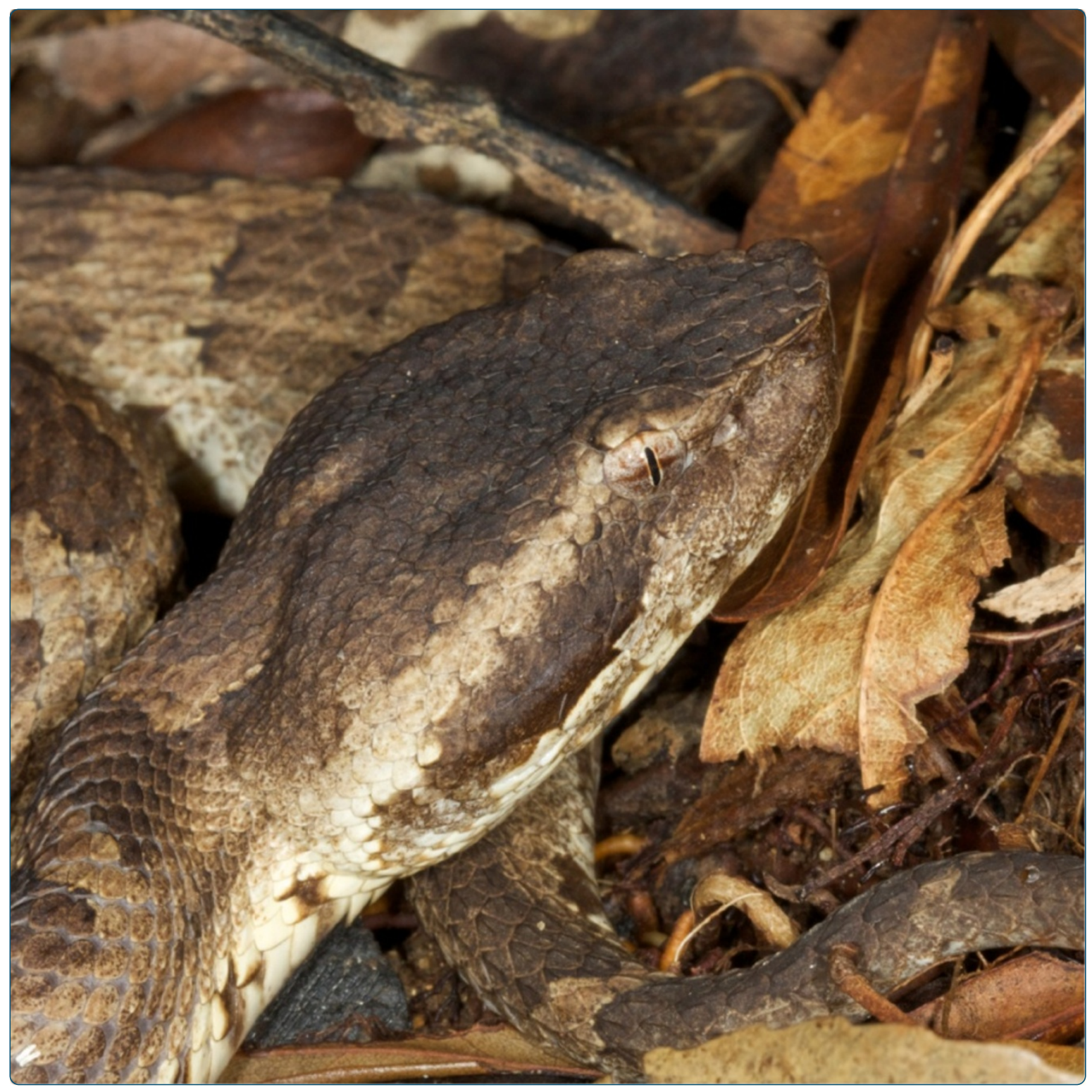

Quantitative high-throughput profiling of snake venom gland transcriptomes and proteomes (Ovophis okinavensis and Protobothrops flavoviridis)

Aird et al.

C Biomed Central

Aird et al. BMC Genomics 2013, 14:790 


\title{
Quantitative high-throughput profiling of snake venom gland transcriptomes and proteomes (Ovophis okinavensis and Protobothrops flavoviridis)
}

\author{
Steven D Aird ${ }^{1 *}$, Yutaka Watanabe ${ }^{1}$, Alejandro Villar-Briones ${ }^{1}$, Michael C Roy ${ }^{1}$, Kouki Terada $^{2}$ and Alexander S Mikheyev ${ }^{1 *}$
}

\begin{abstract}
Background: Advances in DNA sequencing and proteomics have facilitated quantitative comparisons of snake venom composition. Most studies have employed one approach or the other. Here, both Illumina cDNA sequencing and LC/MS were used to compare the transcriptomes and proteomes of two pit vipers, Protobothrops flavoviridis and Ovophis okinavensis, which differ greatly in their biology.

Results: Sequencing of venom gland cDNA produced 104,830 transcripts. The Protobothrops transcriptome contained transcripts for 103 venom-related proteins, while the Ovophis transcriptome contained 95. In both, transcript abundances spanned six orders of magnitude. Mass spectrometry identified peptides from 100\% of transcripts that occurred at higher than contaminant (e.g. human keratin) levels, including a number of proteins never before sequenced from snakes. These transcriptomes reveal fundamentally different envenomation strategies. Adult Protobothrops venom promotes hemorrhage, hypotension, incoagulable blood, and prey digestion, consistent with mammalian predation. Ovophis venom composition is less readily interpreted, owing to insufficient pharmacological data for venom serine and metalloproteases, which comprise more than $97.3 \%$ of Ovophis transcripts, but only 38.0\% of Protobothrops transcripts. Ovophis venom apparently represents a hybrid strategy optimized for frogs and small mammals.
\end{abstract}

Conclusions: This study illustrates the power of cDNA sequencing combined with MS profiling. The former quantifies transcript composition, allowing detection of novel proteins, but cannot indicate which proteins are actually secreted, as does MS. We show, for the first time, that transcript and peptide abundances are correlated. This means that MS can be used for quantitative, non-invasive venom profiling, which will be beneficial for studies of endangered species.

Keywords: Transcriptome, Illumina, proteome, Mass spectrometry, Venom, Okinawa, Viperidae, Crotalinae, Toxins, Enzymes

\section{Background}

Snakes employ a great variety of biochemical compounds to immobilize, kill, and digest their prey $[1,2]$, although whether venom actually augments assimilation efficiency is a matter of continuing debate [2-6]. Biochemical mechanisms employed in prey envenomation involve a complex interplay between venom chemistry and homeostatic mechanisms in the prey; thus, envenomation success depends upon exploiting the prey's biochemistry [1]. Venom composition necessarily reflects both the biology

\footnotetext{
*Correspondence: steven.aird@oist.jp; alexander.mikheyev@oist.jp 'Okinawa Institute of Science and Technology, Tancha 1919-1, Onna-son, Kunigami-gun, Okinawa-ken 904-0412, Japan

Full list of author information is available at the end of the article
}

of the snake and the nature of its principal prey, factors that change ontogenetically and geographically [7-13].

Biochemical components of a venom participate in one or more of three fundamental envenomation strategies. Two of these are prey immobilization strategies and may be denominated "hypotensive" and "paralytic" strategies [1]. Both serve to limit prey flight, in snake taxa which strike, release, and then track their prey (most viperids), or to overcome prey resistance, in snakes that seize and bulldog their prey (many elapids and all colubrids). The third strategy is digestive and commences degradation of prey tissues internally, even before the prey has been engulfed. Normally, all three strategies operate simultaneously and many individual venom components participate in more than one of them. Each of these three strategies

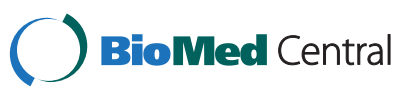


contains interchangeable biochemical constituents. Different venomous taxa employ different combinations of constituents, and no single species employs them all [1].

Snake venom composition can be studied either at the proteomic or the transcriptomic level. Traditionally, snake proteins were sequenced after chromatographic purification, after isolation on polyacrylamide gels, or after cloning cDNA from the venom glands. Although these approaches are typically necessary for studies of protein function, they are laborious, and they are less quantitative than might be desired. Because a relatively small number of individual proteins or clones can be processed at one time, and because techniques vary between labs, comparative analyses of venom chemistry have been difficult $[14,15]$. Wagstaff et al. [16] found $80 \%$ of Echis ocellatus venom proteins identified with mass spectrometry in the corresponding transcriptome, but $67 \%$ of transcripts were not found in the proteome. In a study of Bothropoides pauloensis venom, Rodrigues et al. [17] reported "a low degree of correspondence" between transcriptome and proteome. The degree of correspondence varied, depending upon the protein family. Transcriptome and proteome were in good agreement in regard to bradykinin-potentiating peptides, phospholipases $\mathrm{A}_{2}$, and L-amino acid oxidase, but diverged sharply with regard to metalloproteases and C-type lectinlike components. To date, no study has attempted to perform a rigorous statistical comparison of transcriptome and proteome.

Recent technological advances in mass spectrometry and next generation sequencing have greatly simplified both proteomic and transcriptomic studies of snake venoms. Snake venom transcriptomes are now routinely sequenced on a variety of platforms, allowing examination of many more components than has been possible traditionally. In particular, Illumina sequencing, has allowed more accurate quantification of mRNA composition. However, in addition to venom proteins, next generation cDNA sequencing also detects many non-venom components, and erroneous assemblies are another possible source of error. The advent of LC/MS-based venom proteomics permits high throughput screening of venom components [18]. This approach relies on existing databases of protein sequences, and can be limited by the availability of reference data. LC/MS is not typically used to estimate protein abundance. Used together, next generation CDNA sequencing and LC/MS have considerable power, since mass spectrometry can validate cDNA sequencing. However, relatively few venom studies have combined the two tools $[14,16,19]$. Here both techniques were used to explore the venoms of two Okinawan pit vipers, with the goal of understanding their venom chemistry, and evaluating the performance of LC/ MS as a tool for quantifying venom protein composition.

Okinawa, Japan has two native pit vipers, the Okinawa habu (Protobothrops flavoviridis) and the himehabu (Ovophis okinavensis). Human activities have introduced the Taiwanese habu (Protobothrops mucrosquamatus) and the Sakishima habu (Protobothrops elegans) as well. The two native species differ in nearly all aspects of their biology. The Okinawa habu is semi-arboreal and can reach lengths of $2.5 \mathrm{~m}$. It is active in the warmer months of the year. In contrast, the himehabu is terrestrial, usually not exceeding $70 \mathrm{~cm} \mathrm{[20]} \mathrm{and} \mathrm{is} \mathrm{active} \mathrm{at} \mathrm{temperatures} \mathrm{as} \mathrm{low}$ as $10^{\circ} \mathrm{C}[20,21]$.

Most vipers and pit vipers display a well-documented ontogenetic shift from ectothermic prey (primarily lizards and frogs) to endotherms [22-29]. Protobothrops flavoviridis follows the usual pattern. Nishimura et al. [30] have documented pronounced ontogenetic dietary shifts in Protobothrops. Okinawa habus less than $30 \mathrm{~cm}$ in length feed heavily on lizards (36.3\% of food items). Amphibians comprise only $3 \%$ of the juvenile diet, while house mice (Mus) and Horsfield's shrews (Crocidura horsfieldi) constitute another $60.6 \%$. Subadult and adult Okinawa habus $(50-90 \mathrm{~cm})$ feed less on amphibians $(0.9 \%)$ and lizards (2.4\%), while birds become an important component (7.9\%), and mammals (mice, Horsfield's and Asian house shrews, and rats) become more important (91.7\%). Habus above $1.3 \mathrm{~m}$ become exclusive mammal feeders [30].

Ovophis okinavensis, by virtue of its small adult size, does not exhibit an apparent dietary shift [20]. While it is technically a dietary generalist [20], its seasonal activity is strongly correlated with frog abundance. In many Ovophis populations, frogs comprise nearly $90 \%$ of the food items taken by both juveniles and adults [20,21].

The present study employed Illumina cDNA sequencing and LC/MS to investigate the transcriptomes and proteomes of these two native pit vipers. This was done to further illuminate the composition of these two venoms and to ascertain whether the two techniques were congruent.

\section{Results and discussion}

Transcriptome sequencing, assembly and mapping

After quality filtering, 13,572,340 and 12,184,487 pairedend reads remained, as well as 2,079,603 and 3,110,164 single-end reads, in the Ovophis and Protobothrops libraries, respectively, which were used for the assembly. When re-mapped to the assembly using RSEM, which used only paired-end read data, $90.4 \%$ and $92.0 \%$ of the reads were mapped, with $73.4 \%$ and $86.7 \%$ of these reads being properly paired in alignment. After filtering low-frequency transcripts (less than 1 FPKM), assemblies were reduced from 46,631 and 58,199 transcripts for Ovophis and Protobothrops, respectively, to 13,998 and 19,970 transcripts.

\section{Transcriptomes}

The Protobothrops transcriptome contained partial and complete transcripts for 85 identifiable toxins, representing 21 protein families (Additional file 1: Tables S1 and 
Additional file 2: Table S4). Expression levels spanned nearly six orders of magnitude. In addition, we identified another 18 sequences in nine more families that are either known to contribute to venom function (e.g. glutaminyl cyclase (QC)), or which potentially do so. The latter group includes tissue enzymes that have been recruited into some venomes (e.g. paraoxonase) and purine and pyrimidine biosynthetic enzymes (e.g. adenylosuccinate synthase) that are extremely important in viperid and elapid venoms, but less so in those of crotalids [31]. While 16 families were represented by a single sequence (Additional file 1 : Table S1), others displayed anywhere from 2-21 sequences. Metalloproteases (MPs) (21), serine proteases (SPs) (16), and C-type lectins (CTLs) (12) were the most diversified families in Protobothrops venom (Additional file 1: Table S1); however, the most diversified families are not necessarily the most heavily expressed. Forty of the 103 sequences were identical or nearly so, to sequences previously published for this species. Another 51 were most similar to toxins known from other venomous snake taxa. The remaining 12 were most similar to sequences from other vertebrate taxa, including amphibians, lizards, and mammals; thus, in total there were an estimated 63 new sequences for this species, including the 12 that were novel for snakes.

The Ovophis transcriptome contained 76 transcripts for identifiable toxins belonging to 19 toxin families (Additional file 3: Tables S2 and Additional file 4: Table S5). Purine and pyrimidine biosynthetic enzymes, acetylcholinesterase, and glutaminyl cyclase comprised another 20 transcripts. The range of expression levels was similar to that seen in the Protobothrops transcriptome. In the Ovophis transcriptome, SPs were the most diversified family (26 sequences), followed by MPs (10), and CTLs (8). Only one sequence, a phospholipase $A_{2}$, has been previously published for this species. Another 81 sequences were most similar to those of other snakes, while 13 were most similar to sequences from the iguanid lizard, Anolis carolinensis. In total, 94 partial and complete sequences reported herein appear to be new for Ovophis okinavensis.

The two transcriptomes revealed fundamentally different envenomation strategies (Figure 1; Additional file 5: Table S3). In Protobothrops venom glands, phospholipases $\mathrm{A}_{2}\left(\mathrm{PLA}_{2}\right)$ (32.1\% of all transcripts) and metalloproteases (27.0\%) were the dominant constituents, followed by Factor IX/X activators (11.6\%), SP transcripts (11.1\%), and L-amino acid oxidase (LAO) (9.1\%) (Additional file 1: Table S1 and Additional file 5: Table S3; Figure 1). Thus, these five protein classes accounted for $90.9 \%$ of all transcripts. In Ovophis venom glands, SPs were the dominant component (93.1\%), followed by MPs (4.2\%), PLA 2 (0.65\%), LAO (0.62\%), and C-type lectin-like proteins (CTL) (0.47\%), (Additional file 3: Table S2 and Additional file 5: Table S3; Figure 1). Thus, in Ovophis, the dominant five classes comprise $99.0 \%$ of total venom transcripts.

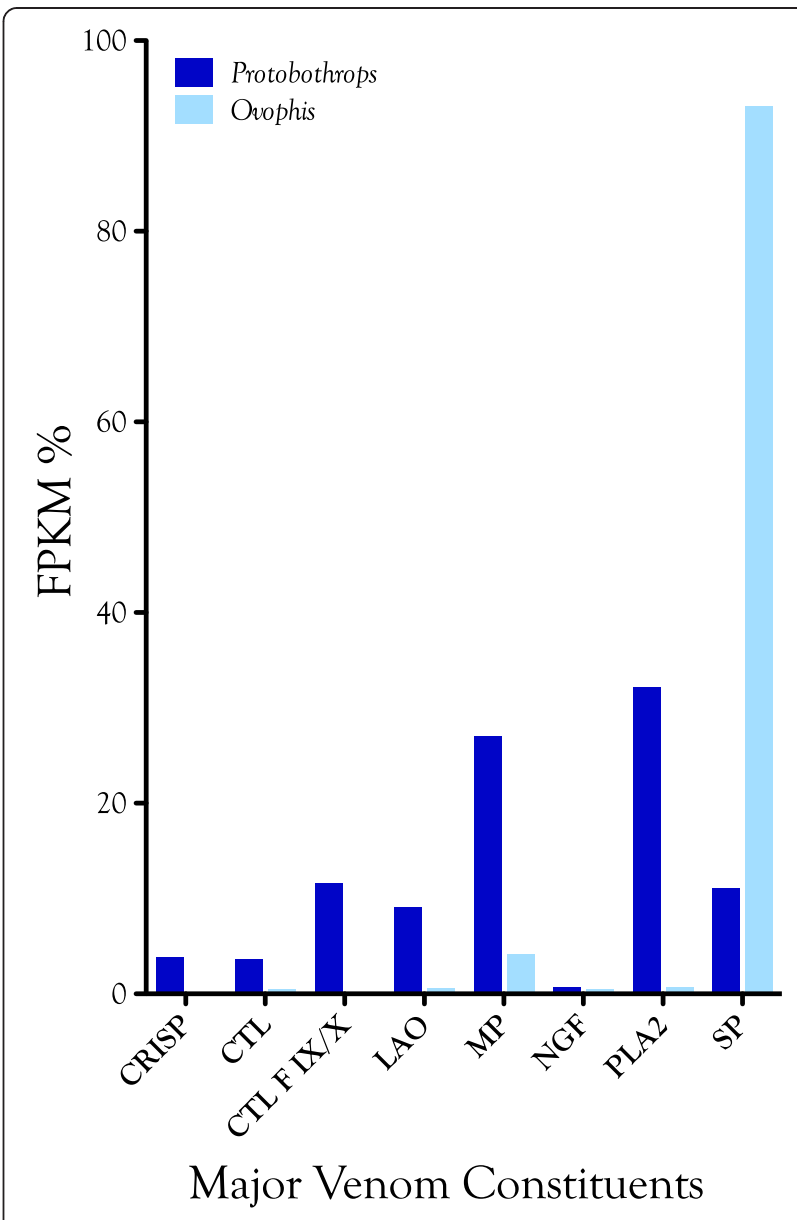

Figure 1 Abundance of cDNA transcripts in venom glands of Protobothrops flavoviridis and Ovophis okinavensis, as a percentage of the respective transcriptomes. Abundant transcripts mask the presence of most venom constituents, some of which are six orders of magnitude $\left(10^{6}\right.$-fold) less abundant. For the sake of legibility, only toxins comprising $\geq 1 \%$ of either transcriptome are shown here. Toxin class abbreviations are as follows: CRISP, cysteine-rich secretory proteins; $C T L$, C-type lectin-like proteins; CTL F IX/X, C-type lectin-like activators of Coagulation Factors IX/X; LAO, L-amino acid oxidase; MP, metalloproteases; NGF, nerve growth factor; PLA $A_{2}$ phospholipase $A_{2}$; and $\mathrm{SP}$, serine proteases. These two venoms are starkly different in composition. Protobothrops venom comprises modest titers of eight toxin families, while Ovophis venom consists overwhelmingly of SPs (93.1\%) with a lesser quantity of MPs (4.2\%). Both venoms contained arrays of lesser constituents, which also varied dramatically between the two species.

Significant differences are also evident in terms of minor components (Additional file 5: Tables S3, Additional file 2: Table S4 and Additional file 4: Table S5). Three-finger toxins (3FTx), paraoxonase, vespryn, and waprin transcripts were found in the Protobothrops transcriptome, but were absent in Ovophis. Five acetylcholinesterase (AChE) transcripts and crotasin-like transcripts were found in the Ovophis transcriptome, but not in that of Protobothrops. Glutaminyl cyclase (QC) cDNA was detected at lower levels in the Ovophis transcriptome. 5'-nucleotidase, CRISP, CTL, nerve growth factor (NGF), and phosphodiesterase 
(PDE) transcripts were significantly more abundant in Protobothrops venom, whereas dipeptidyl peptidase IV (DPP IV) was more abundant in Ovophis venom glands (Additional file 5: Table S3).

Both transcriptomes also contained numerous transcripts that appear unrelated to envenomation (Additional file 6: Table S6 and Additional file 7: Table S7). The majority of these appear to be cellular proteins and were transcribed at very low levels. Peptides were also isolated for many of these (Additional file 6: Table S6 and Additional file 7: Table S7). Whether such constituents make a significant contribution to envenomation is unknown, but it seems unlikely.

\section{Proteomes}

Peptides were isolated from $100 \%$ of venom or venomrelated transcripts that were more abundant than contaminants (e.g. human keratin) (Additional file 1: Table S1 and Additional file 3: Table S2). Peptides were also isolated from at least 18 transcripts in the two transcriptomes that occurred below contaminant levels (Additional file 2: Table S4 and Additional file 4: Table S5).

\section{Comparison between proteomic and transcriptomic data sets}

Although one would expect to find strong correlations between venom gland mRNA and protein profiles, such a link has been elusive [32]. Lack of correlation between the two types of data may be due to biological reasons, such as biased processing of messenger transcripts. Alternatively, purely technical reasons may have prevented accurate estimation of cDNA or protein abundance, particularly in early studies in which sequencing by the Sanger method limited the number of clones. Although our measure of protein abundance was relatively crude, we were nonetheless able to detect a correlation (Protobothrops flavoviridis $\mathrm{r}=0.77, \mathrm{p}<2.2 \mathrm{e}^{-16} ;$ Ovophis okinavensis $\mathrm{r}=0.70, \mathrm{p}<1.1 \mathrm{e}^{-12}$ ) between mRNA and venom protein levels (Figure 2).

We were able to confirm the correlation between proteomic and transcriptomic estimates of protein abundance using publicly available data from NCBI (Additional file 8: Figure S1). There were no proteins detected in the NCBI data set that were missing from our transcriptome, suggesting that we were able to capture all of the transcriptional diversity. The robustness of the result also argues against a spurious correlation driven by poor assembly and mapping of low FPKM transcripts.

The correlation, although significant, explained only about half of the variance in the data. Apparent differences between mRNA and protein levels may stem from several factors, both biological and analytical. For example, although tissue and venom samples were taken from the same individuals, they were taken at different times. If venom components are synthesized at different rates the two measurements might not agree. Likewise, it is possible that due to extensive post-translational modification of many venom components, not all messenger transcripts have an equal chance of becoming mature proteins. It is also likely that our measure of protein abundance is not sufficiently precise, due perhaps to biased cleavage of proteins or biases in ion detection during LC/MS. Proteins differ in their susceptibility to enzymatic digestion. Even though three proteases (chymotrypsin, Glu-C, and trypsin) were used, few proteins were digested equally well by all three. More abundant peptides are much more likely to be detected by mass spectrometry than others. Lastly, it is probable that incomplete transcripts stemming from the short read length diminished the strength of the correlations. Newer Illumina sequencer models (e.g., MiSeq) now boast read lengths as great as $500 \mathrm{bp}$, which may mitigate this problem in future studies.

There are a large number of toxin and potential toxin transcripts that are expressed at near-zero levels (Additional file 1: Table S1, Additional file 2: Table S4, Additional file 3: Table S2, Additional file 4: S5, Additional file 5: Table S3). These include 3-finger toxins, AChE, acid phosphomonoesterase, crotasin-like proteins, paraoxonase, tissue factor pathway inhibitor (TFPI), vespryns, waprins, and many MP and SP transcripts. There is no evidence that many of these are actually translated, or, if they are, they are not a substantial proportion of the proteome. This raises the question of what function these transcripts may now have, or may have had previously. Are these merely tissue transcripts that have not actually been incorporated into the venome? How high an expression level would be required before novel venom proteins would have selective value, or would be under selective pressure? Undoubtedly selective pressure would vary with the biochemical envenomation strategy employed by the taxon in question, and also upon the nature of the contribution made by a given toxin to that strategy. Given the massive overkill that most venoms generate, it is likely that a substantial contribution would be required to generate much selective pressure. It also seems likely that there would be more selective pressure to increase prey immobilization efficiency than acute toxicity or assimilation efficiency.

\section{Major venom constituents Metalloproteases}

Snake venom MPs are presently classified into four groups, according to domain structure and size: P-I MPs possess a metalloprotease domain only and are largely hemorrhagic; P-II MPs are larger, with metalloprotease and disintegrin domains; P-III enzymes have metalloprotease, disintegrin, and cysteine-rich domains; and P-IV enzymes have a lectinlike domain linked by disulfide bonds to a P-III structure [33]. The structural complexity of P-III enzymes has resulted in greater functional diversity. They promote 


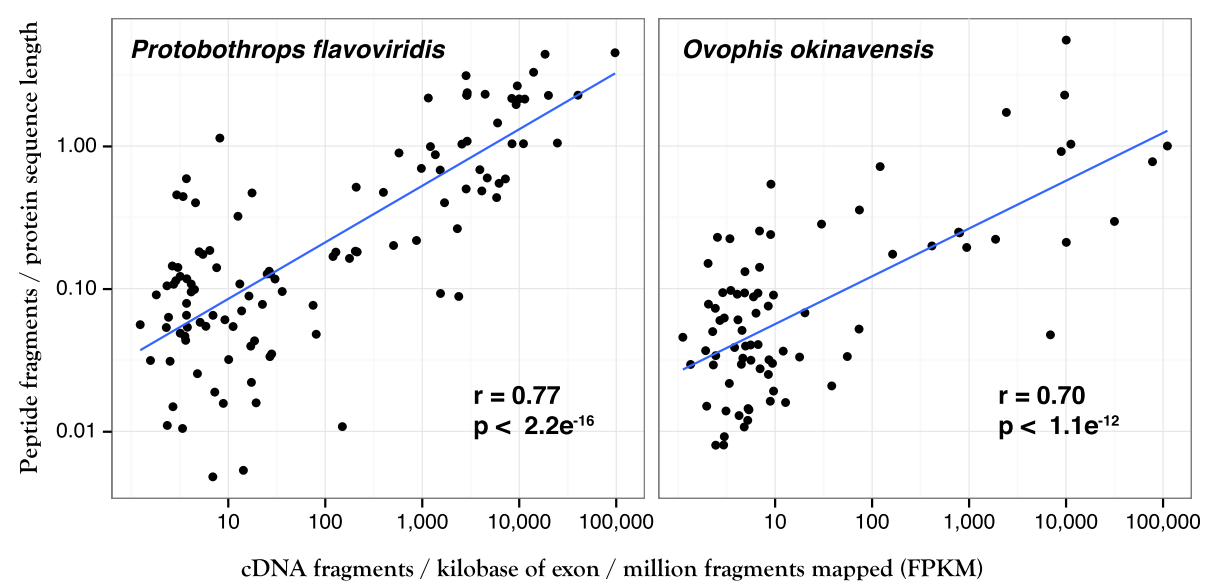

Figure 2 Gene expression in the venom glands correlates well with protein abundance in the venom. In both cases the correlation was strongly significant, although roughly half of the variance remained unexplained. These data show that mass spectrometry can provide quantitative data on protein abundance in snake venom proteomes. A similar pattern can be seen using publicly available snake venom proteins from NCBI as a protein reference (Additional file 8: Figure S1), suggesting that this technique should also work without species-specific transcriptomic data.

hemorrhage, inflammation, apoptosis, and prothrombin activation, while inhibiting platelet aggregation. As a general rule, P-III enzymes are more potent hemorrhagins than P-I enzymes [33]. In addition to degrading vascular endothelial basement membrane (hemorrhagins), collectively, MPs exhibit diverse and variable combinations of activities. Some anticoagulant metalloproteases degrade only the fibrinogen A $\alpha$ chain [34], while others degrade one or more chains of both fibrinogen and fibrin with varying specificity [34-36]. Still others release histamine [37], antagonize platelet aggregation by different mechanisms [38-41], or activate [42] or digest plasminogen [43]. Some are procoagulant, possessing Factor Xa-like activity [44]. Few laboratories have exhaustively assayed MPs for potential biological and biochemical activities; thus, inferring such functions from structure is almost impossible. The same may be said of SPs.

The Protobothrops transcriptome contained transcripts for twelve P-II MPs and nine P-III MPs. One of the P-II enzymes (MP 01) constituted $11.06 \%$ of all toxin transcripts and collectively P-II transcripts accounted for barely $\sim 11.1 \%$ of the transcriptome (Additional file 9: Figure S2; Additional file 1: Tables S1, Additional file 5: Table S3, and Additional file 2: Table S4). P-III transcripts were more abundant, comprising $15.8 \%$ of all transcripts. Three sequences were homologous to hemorrhagic proteases HR1A and B $[45,46]$. The Ovophis transcriptome included seven P-II transcripts and three P-III transcripts. In Ovophis, P-II transcripts represented only $1.6 \%$ of all transcripts (Additional file 3: Table S2 and Additional file 4: Table S5). P-III transcripts added another $2.6 \%$. Thus MPs comprised a mere $4.2 \%$ of the Ovophis transcriptome, compared to $26.9 \%$ in Protobothrops (Figure 1, Additional file 9: Figure S2 and Additional file 10: Figure S3;
Additional file 3: Table S2, Additional file 5: Table S3, and Additional file 4: Table S5).

Of the 21 Protobothrops MPs, peptides were sequenced by mass spectrometry for 15 , with coverage ranging from 31.1-91.4\% of the respective transcripts (Additional file 1: Table S1). Peptide coverage of Ovophis MPs ranged from 26.9-80.6\% (Additional file 3: Table S2).

\section{Phospholipases $A_{2}$}

The Protobothrops transcriptome contained four transcripts for $\mathrm{PLA}_{2} \mathrm{~S}$ (Additional file 1: Table S1), including a Lys-49 myotoxin $\left(\mathrm{PLA}_{2} 4\right)$ [Accession \#: AB851948] and a weak neurotoxin similar to trimucrotoxin [47] $\left(\mathrm{PLA}_{2} 2\right)$ [AB848131]. PLA 21 [AB848154] accounted for 26.7\% of all transcripts, while PLA $_{2} 2$ amounted to an additional 5.5\% (Additional file 1: Table S1 and Additional file 2: Table S4). The Ovophis transcriptome contained two PLA transcripts; however, the more abundant transcript, $\mathrm{PLA}_{2}$ 1 , comprised only $0.65 \%$ of the transcriptome (Additional file 3: Table S2 and Additional file 4: Table S5) [AB848270]. Peptides sequenced by mass spectrometry covered $98.3 \%$ of $\mathrm{PLA}_{2} 1$, but no peptides were found for the minor transcript.

\section{Serine proteases}

Of the 18 SP transcripts in the Protobothrops library (Additional file 1: Table S1 and Additional file 2: Table S4), only two (SP01 and SP 12) (FPKM\% 2.6 and almost zero, respectively) can be confirmed as complete (Additional file 11: Figure S4). Several transcripts appear to encode dysfunctional SPs. For instance, SP16 encodes 36 residues and is bracketed on both ends by stop codons (Additional file 1: Table S1; Additional file 11: Figure S4). Given that it was expressed at a very low level and that no peptides 
were sequenced by mass spectrometry, we think it is unlikely to play any role in envenomation.

SP01, the most abundant SP transcript, corresponds to a protein that appears in the literature under the names of habutobin [48-51] and flavoxobin [52-56], a weakly thrombin-like enzyme of 242 amino acids that specifically releases fibrinopeptide A from fibrinogen [55]. No information is available with regard to possible kallikrein-like activity. However, Yamamoto et al. [56] found that flavoxobin is an active C3-convertase that selectively releases $\mathrm{C} 3 \mathrm{~b}$ and C3a. It remains active in blood containing endogenous protease inhibitors, and promotes massive $\mathrm{C} 3$ consumption, and to a lesser extent, C5 cleavage. A kinin-releasing enzyme, flavoviridiobin, is also known from this venom [57]; however, since no sequence data are available, we cannot identify it among our transcripts. Enzymatic digests of crude venom effected with trypsin, chymotrypsin, and Glu-C (Pierce) yielded peptides that accounted for $94.6 \%$ of the primary structure of SP01 (Additional file 1: Table S1; Additional file 11: Figure S4). Reasonable peptide coverage of transcripts as minor as $0.24 \%$ (SP11, 50.0\%) was achieved (Additional file 1: Table S1).

In contrast to the Protobothrops library, the Ovophis library contained transcripts for 26 different SPs (Additional file 1: Table S1 and Additional file 2: Table S4; Additional file 12: Figure S5). Peptide coverage of $36 \%$ or above was achieved for 22 of these, with coverage above $70 \%$ for 11 of them. Two transcripts (SP09 and 10) appear to be plasminogen activators, while SP20 is most similar to a kinin-releasing enzyme from the venom of Bothrops jararaca. Serine proteases display numerous amino acid substitutions, and the structural determinants that specifically account for kinin-releasing activity are unknown [58]. The difficulty in assigning pharmacological activities to specific sequence variations is immediately apparent upon a cursory examination of Additional file 11: Figure S4 and Additional file 12: Figure S5.

Wu et al. [59] reported a novel class of inactive serine protease homologs $(\mathrm{SPH})$ that displayed an arginine substitution for His-43 of the catalytic triad. SP13 was the only serine protease in our Protobothrops library that showed this His $\rightarrow$ Arg mutation (Additional file 12: Figure S5, position 126); however, the Ovophis library contained eight transcripts with $\mathrm{His} \rightarrow \mathrm{X}$ substitutions (Additional file 12: Figure S5, position 101). Two of these, SP08 and SP22 showed His $\rightarrow$ Lys substitutions; two putative thrombin-like enzymes, SP16 and SP17 displayed $\mathrm{His} \rightarrow$ Asn substitutions, and SP07 had a His $\rightarrow$ Ala substitution. Numerous other sequence differences appear in that transcript as well (Additional file 12: Figure S5). SPHs from other sources have been shown to possess diverse activities, so it is possible that inactive SPs in venoms have developed other unknown functions, some of which may be specialized for particular prey types.
An inactive catalytic triad is but one of many structural differences manifested by Ovophis SPHs (Additional file 12: Figure S5). Almost all of the cysteine residues are in different positions as well (Cys-102 has only moved to position 100, but most have shifted substantially more), although within the group, most residues are conserved across most sequences. SP07 is a marked exception in the latter regard (Additional file 12: Figure S5). Another oddity among these sequences is that four of them (SP01, 07, 23, and 26) are truncated C-terminally with stop codons, despite the fact that SP01 and 07 display expression levels of 9.6 and $7.1 \%$, respectively. Wang et al. [60] reported that a Kentucky population of Crotalus horridus lacks an acidic $\mathrm{PLA}_{2}$ because the codon for $\mathrm{Tyr}^{22}$ has mutated into a stop codon. They concluded that low PLA 2 expression levels in most Crotalus horridus venoms can be attributed to translation blockage. At this point, it is difficult to know how widespread this phenomenon might be, but it is apparent that these two Ovophis SPs are translated effectively since they had ample peptide coverage (Additional file 3: Table S2).

\section{L-amino acid oxidase}

The Protobothrops transcriptome included two transcripts for L-amino acid oxidase [AB848142, AB848143], comprising $2.3 \%$ and $6.8 \%$ of all transcripts, respectively (Figure 1; Additional file 1: Table S1). A single LAO transcript was present in Ovophis glands [AB848269], representing 0.6\% of the transcriptome (Additional file 3: Table S2). Peptides accounting for $84.6 \%$ and $70.8 \%$ of Protobothrops LAO 1 and LAO 2, respectively, and $78.7 \%$ of the Ovophis LAO transcript sequence was identified by mass spectrometry (Additional file 1: Table S1 and Additional file 3: Table S2).

\section{Minor venom constituents}

\section{Cysteine-rich secretory proteins}

Two CRISPs were identified in the Protobothrops transcriptome (Additional file 1: Table S1 and Additional file 2: Table S4). CRISP 1 [AB848115], (FPKM = 3.9\%) for which a complete transcript was obtained, is identical to triflin [61], but CRISP 2 [AB851959] aligns best with a CRISP bearing an EGF-like calcium-binding domain from the venom of Crotalus adamanteus [62] (Additional file 2: Table S4). However, the putative 39-residue EGF domain in the $C$. adamanteus toxin does not align well with the corresponding region of the Protobothrops transcript. The latter contains only four acidic residues, compared with nine in the $C$. adamanteus sequence. Only three of the five $C$. adamanteus cysteine residues match, and the two sequences require a two-residue gap to achieve even this poor alignment. Therefore, we think it unlikely that there is a functional EGF-like calcium binding domain in the Protobothrops toxin. Moreover, no peptides were sequenced for this odd CRISP, whereas $84.6 \%$ of CRISP 1 was sequenced. 
A single, complete CRISP transcript (FPKM $=0.2 \%)$ was identified in the Ovophis transcriptome (Additional file 2: Table S2) [AB848276], but sequenced peptides accounted for $89.0 \%$ of its primary structure. It was most similar to a CRISP from the venom of Bothriechis schlegelii [GenBank: ACE73559.1].

CRISPs are generally not abundant components of snake venoms, but they are widely distributed taxonomically. Ablomin (Gloydius blomhoffii), triflin (Protobothrops flavoviridis) and latisemin (Laticauda semifasciata) are L-type $\mathrm{Ca}^{2+}$ channel antagonists of depolarization-induced arterial smooth muscle contraction, but they do not affect caffeine-induced contraction [61]; thus they promote vasodilation and hypotension. Tigrin from "venom" of the Japanese colubrid, Rhabdophis tigrinus, affected neither. This is probably because Rhabdophis venom glands are not secretory in nature. Instead, Rhabdophis glands sequester toxins from the blood stream that are derived from the toads that Rhabdophis eats [63]. Thus, tigrin is most likely an amphibian toxin, intended for oral or gastric activity, and not a snake toxin, designed for direct vascular action. In contrast, patagonin, a CRISP isolated from the venom of the colubrid, Philodryas patagoniensis, damaged murine skeletal muscle [64].

\section{Nerve growth factor}

Both habu transcriptomes contained a single, complete transcript for nerve growth factor [Pf: AB848144; Oo: AB848271] (Additional file 1: Table S1 and Additional file 3: Table S2). The Protobothrops transcript accounted for $0.7 \%$ of all transcripts while the Ovophis transcript accounted for $0.5 \%$. Both transcripts are translated and peptides were isolated by mass spectrometry. NGFs function as arginine esterases $[65,66]$, so they probably contribute to venom hypotensive activity via nitric oxide liberation and histamine release $[67,68]$. Mouse salivary NGFs activate plasminogen, their only known action upon a biologically important, non-neural substrate $[69,70]$, but it is not clear whether snake venom NGFs can also do this. If so, they would hinder blood clotting.

\section{C-type lectins}

Snake venom C-type lectins, or snaclecs [71] are commonly found in pit viper venoms. These proteins differ from classical C-type lectins in that they lack the calcium and sugarbinding loop and instead bind to a large variety of proteins and receptors involved in hemostasis, including coagulation factors IX and X and various blood platelet receptors [72]. They may consist of one, two, or four $\alpha \beta$ heterodimers, and in some cases, the heterodimer is incorporated into a metalloprotease [73]. In many CTLs, dimers are formed by domain swapping between subunits [73].

CTL pharmacology is quite complex. Taniuchi et al. [74] found that flavocetin A actually induces formation of small platelet aggregates, but the dose-dependency is bell-shaped, with a maximum effectiveness at $1-2 \mu \mathrm{g} / \mathrm{mL}$. Clemetson [72] lamented that because so much venom research is now done at the transcriptional level, the protein chemistry and pharmacology necessary to understand CTL diversity has lagged way behind. In reality, the same could also be said of any other toxin family that shows significant diversification, such as 3FTxs, SPs, MPs, and PLA $\mathrm{A}_{2} \mathrm{~s}$.

Venom C-type lectins may activate platelets or inhibit platelet activation, but either mechanism serves the function of inducing thrombocytopenia. Because C-type lectins are non-enzymatic, a 1:1 stoichiometry exists between these toxins and their targets. Clemetson [72] noted that for this reason, it is much more efficient to clear platelets by activating them than by inhibiting them. However, different species of snakes employ both strategies, and it is probably necessary to look at all the toxins in a given venom that impact hemostasis, before drawing any conclusions.

Twelve Protobothrops CTL transcripts included three $\alpha$-chains and three $\beta$-chains homologous to flavocetin $A$, an $(\alpha \beta)_{4}$ inhibitor of von Willibrand factor-induced, GP1Bmediated platelet aggregation [75,76] and convulxin, a potent $(\alpha \beta)_{4}$ inducer of platelet aggregation that binds to GPVI [73] (Additional file 13: Figure S6; Additional file 1: Table S1 and Additional file 2: Table S4). One of the flavocetin A-like $\alpha$-chains (CTL03 $\alpha$ ) and CTL07 F IX/X displayed a number of sequence differences, including an unusual C-terminus (CKFLRPR). Whether these have any pharmacological significance is unknown. In addition to toxins that target blood platelets, there were five A chains and one $\mathrm{B}$ chain for proteins that bind to coagulation Factors IX/X (Additional file 1: Table S1 and Additional file 2: Table S4). Factor IX/X binding proteins inhibit blood coagulation by blocking the host clotting cascade [77].

Seven Ovophis CTL transcripts apparently all encode proteins that affect platelet activation (Additional file 3: Table S2 and Additional file 4: Table S5; Additional file 13: Figure S6). They are homologous to flavocetin A and convulxin. We did not discover any Ovophis transcripts that encode anticoagulant Factor IX/X-binding proteins. Our Ovophis cDNA library contained one $\alpha$-chain, CTL1 $\alpha$, similar to the $\alpha$-chain of flavocetin A (Protobothrops flavoviridis) and the convulxin A- and C-chains (Crotalus durissus terrificus) (Additional file 13: Figure S6). CTL1 $\alpha$ is most like crotacetin (Crotalus durissus terrificus. It represented $0.16 \%$ of all transcripts. In addition, there were six $\beta$-chains, homologous to the flavocetin A $\beta$-chain and the convulxin B- and D-chains (Additional file 13: Figure S6; Additional file 3: Table S2). Together these seven CTLs represented $0.47 \%$ of all transcripts.

\section{Bradykinin-potentiating peptides}

A single bradykinin-potentiating peptide (BPP) was sequenced from Protobothrops venom using mass spectrometry 
(QSKPGRSPPISP) (Additional file 1: Table S1), confirming the existence of a BPP proposed by Higuchi et al. [78], on the basis of a cDNA transcript. A second possible BPP (VVVQPHESPAGGTTA) was also sequenced, but to date, no other BPPs have been found with proline immediately after the $\mathrm{N}$-terminal pyroglutamic acid, making this sequence suspect. Moreover, the VVV-sequence, N-terminal to the glutamine, and the C-terminal AGGTTA-sequence are highly questionable. Possibly this peptide could be processed to QPHESP. This possible BPP is located at the C-terminus of our BPP transcript; however, our BPP transcript is incomplete, since it lacks a stop codon and it does not include the C-type natriuretic peptide-coding region reported by Higuchi et al. [78] (Figure 3).

Our Protobothrops transcript [AB851926] also contains the second BPP sequence reported by Higuchi et al. [78], although this BPP was not identified by mass spectrometry. They posited the existence of two BPPs based on the assumptions that such sequences should possess glutamine at the $\mathrm{N}$-terminus and proline at the $\mathrm{C}$-terminus, and should be about 11 residues in length. In fact, BPPs from three to 14 residues have been reported [79,80] (Additional file 14: Figure S7). Both the Higuchi Protobothrops transcript and ours suggest another probable BPP with the sequence QWMPGGRPPHHIPP (Figure 3). The Gloydius transcript of Higuchi et al. [78] also contains a tripeptide (QWS) that occurs in five locations at the end of the BPPs that they predicted (Figure 3). Two tripeptides from Bothrops insularis venom having pyroglutamic acid at the N-terminus (QQK, QKW) were sequenced by Cintra et al. [79], and these peptides were shown to have bradykinin-potentiating activity on guinea pig ileum (Additional file 14: Figure S7). It is possible that the peptide QWS is likewise biologically active. Other tripeptides are found in the Higuchi Protobothrops and Gloydius transcripts and in our Ovophis transcript. These have the sequences QER (Protobothrops) and QAR (Gloydius and Ovophis) (Figure 3, residues 281-283). All of these are immediately $\mathrm{N}$-terminal to nonapeptides that could also be BPPs (Figure 3, residues 284-292). These sequences are as follows: Pf, QKWGRMVQP; Gb, QNWARMVNP; Oo, QKWGRMVPP.

In addition to being truncated on the $\mathrm{C}$-terminal end relative to the Higuchi transcript, our transcript displays a significant $\mathrm{N}$-terminal extension, containing three additional possible BPPs (Figure 3). These have the sequences QRRV HGGERIWP, QSARLDSTRLGSAP, SRPPSLPAPAQP; however, additional work will be necessary to determine whether these sequences are actually hypotensive and whether they are actually expressed in habu venom.

Our Ovophis BPP transcript [AB852004] displayed a C-terminal stop codon, but was incomplete on the $\mathrm{N}$ terminal end. However, the Ovophis transcript did contain a sequence for a C-type natriuretic peptide (GVAKGCF GLKLDRIGTMSGLGC) that was identical to that reported for Gloydius blomhoffii venom [78] (Figure 3). It differed at five residues from the Higuchi Protobothrops transcript (Figure 3).

When mass spectrometry was used to analyze crude Ovophis venom for the presence of BPPs, the sequence

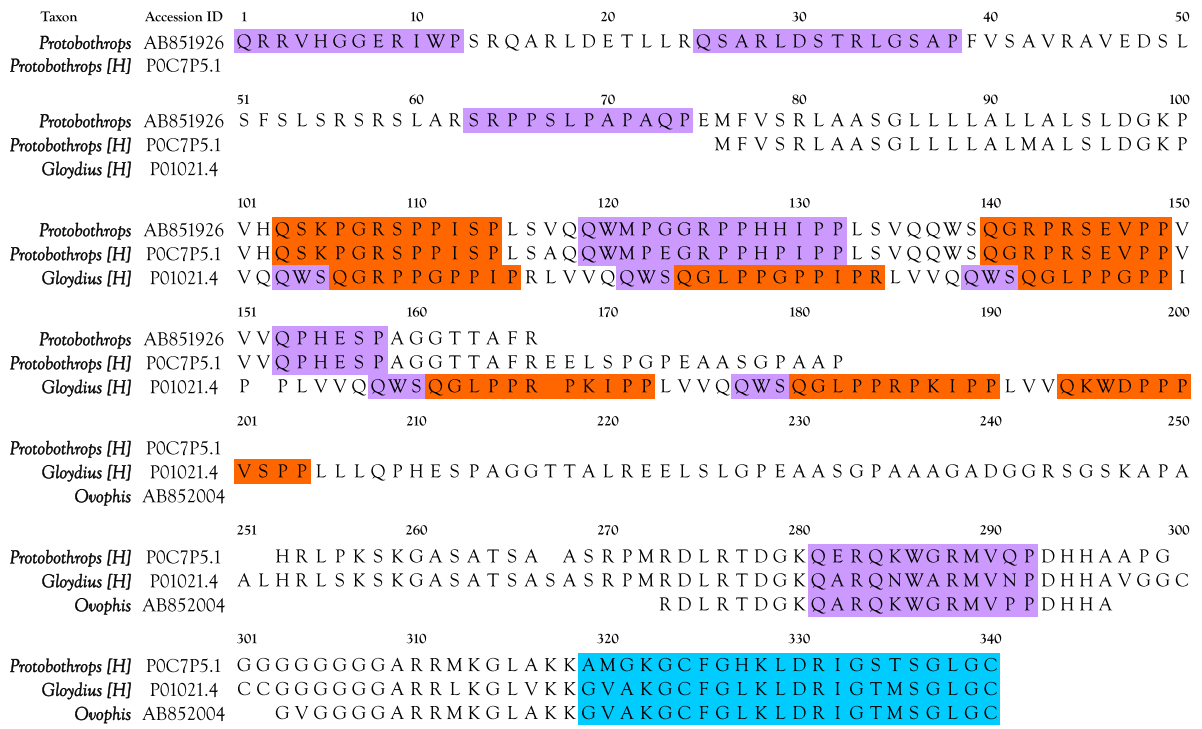

Figure 3 Alignment of the Protobothrops flavoviridis [AB851926] and Ovophis okinavensis [AB852004] BPP/CNP transcripts with those of Higuchi et al. [78] for Protobothrops flavoviridis and Gloydius blomhoffii. Peptides posited by Higuchi et al., or actually sequenced by mass spectrometry in the present study are shown in red. Possible additional BPPs identified in the present study are shown in violet. CNP sequences are highlighted in aqua. 
RPPGPPIPP, and derivative forms thereof (PPGPPIPP and GPPIPP) were isolated. This sequence does not occur in our truncated transcript; however, it is nearly identical to a proposed BPP from the N-terminal end of a BPP-CNP transcript from Gloydius blomhoffii (RPPGPPIPR) [78,81] and from Bothrops jararaca venoms [80] (Figure 3 and Additional file 14: Figure S7).

Potency of bradykinin-potentiating peptides (BPPs) increases $\sim 200$-fold if the $\mathrm{C}$-terminal proline residue is doubled [82]. While the C-terminal tripeptide of a BPP from Gloydius halys venom was shown to be essential for its activity, removal of the $\mathrm{N}$-terminal pyroglutamate residue made it twice as potent [82]; thus, while the $\mathrm{N}$ terminal pyroglutamate common to BPPs (Additional file 14: Figure S7) may prevent their rapid degradation by prey aminopeptidases, it is actually an impediment to bradykinin potentiation. Interestingly, bradykinin-potentiating activity is not correlated with inhibition of angiotensinconverting enzyme (kininase II) activity [82,83], which is much too slow to be relevant to envenomation.

Various studies have shown that bradykinin potentiation and inhibition of somatic angiotensin-converting enzyme (sACE) by pit viper hypotensive peptides are independent biochemical activities [84-89]. The presence of paired proline residues at the $\mathrm{C}$-terminus and a pyroglutamic acid residue at the $\mathrm{N}$-terminus are not the only requirements for bradykinin-potentiating activity or sACE inhibition. Guerreiro et al. [86] have shown that argininosuccinate synthetase is activated by a BPP from Bothrops jararaca venom, indicating that nitric oxide formation represents yet another means by which BPPs promote hypotensive shock to limit prey flight [1].

\section{Phospholipase B}

Phospholipase B (PLB) activity was first reported in snake venoms by Doery and Pearson [90], who confirmed its presence in the venoms of Naja naja, Pseudechis porphyriacus, and Agkistrodon piscivorus. In 1987, PLB from Pseudechis colletti venom was characterized for the first time [91]. No venom PLB sequences were reported until 2011, when transcripts were isolated from venoms of Drysdalia coronoides [92] and Crotalus adamanteus [62]. While PLB accounted for only $0.06 \%$ of all transcripts in those species, it represented $0.14 \%$ of Protobothrops [AB848155], and $0.15 \%$ of Ovophis transcripts [AB848284, AB848285] (Additional file 1: Table S1, Additional file 3: Table S2, Additional file 5: Table S3). Peptides covering 26.1\% of the Protobothrops sequence and 50.5\% and 61.6\% of the two Ovophis sequences, respectively, were isolated by mass spectrometry (Additional file 1: Table S1 and Additional file 3: Table S2; Figure 4). To the best of our knowledge, these are the first protein sequence data for any snake venom PLB.
Feola et al. [93] found that in rabbits, i.v. injections of phosphatidylethanolamine (PE) and phosphatidylserine (PS) caused significant hypotension, cardiac arrhythmias, bronchospasm, activation of intravascular coagulation, complement, platelets, and leukocytes with release of histamine, serotonin, and thromboxane at a dose of $0.10 \mathrm{mg} / \mathrm{kg}$ and caused cardiac arrest and death at a dose of $0.30 \mathrm{mg} / \mathrm{kg}$. All of these effects are consistent with snake venom envenomation strategies [1]; however, it is not clear whether intact PE and PS are released from cell membranes by pit viper venoms. Kinoshita et al. [94] found that PS and PE were not released from membranes by purified Protobothrops flavoviridis phospholipase $\mathrm{A}_{2}$; however, one would not really expect this, and venoms contain many other components in addition to phospholipase $\mathrm{A}_{2}$. What is more, prey tissue destruction by venom components liberates many endogenous compounds, further complicating the picture. At present, the role of PLB in envenomation remains unclear, beyond its generalized hydrolysis of cell membrane phospholipids.

\section{Phosphodiesterase}

The Protobothrops transcriptome contained four phosphodiesterase (PDE) transcripts, ranging from 0.33-0.56\% of all transcripts (Additional file 1: Table S1), which comprised, in aggregate, $0.2 \%$ of the transcriptome [AB848150, AB848151, AB848152, AB848153]. Peptides covering 53.4$56.8 \%$ of the four PDE sequences were sequenced by MS. PDE was less diversified in Ovophis (Additional file 3: Table S2). Two PDE transcripts accounted for a negligible portion of the Ovophis transcriptome [AB851989, AB851990]. Sequenced peptides accounted for only 7.8$13.0 \%$ of the two PDE sequences.

\section{Vascular endothelial growth factor-like proteins}

Five VEGF isoforms comprised just over $0.008 \%$ of all Ovophis transcripts [AB852007, AB852008, AB852009, AB852010, AB848274], while three Protobothrops transcripts totaled $0.32 \%$ of that transcriptome [AB848141, AB851940, AB851941] (Additional file 1: Table S1, Additional file 2: Table S4, Additional file 3: Table S2, Additional file 4: S5, Additional file 5: Table S3). Fourteen unique peptides were isolated for Protobothrops VEGF 1, accounting for $81.1 \%$ of its sequence. Fourteen peptides were also sequenced from Ovophis VEGF 5, amounting to 60.3\% coverage (Additional file 1: Table S1 and Additional file 3: Table S2).

Both venomes contain transcripts for several structural subclasses of VEGFs, although owing to the great diversification of these sequences, classification is difficult. For instance, Ovophis VEGF 1 possesses a 24-residue insert seen in no other sequence (Figure 5). Ovophis VEGF 1 and 2 and Protobothrops VEGF 2 all possess long C-terminal extensions and align well with human VEGF-A $\mathrm{A}_{165}$ (Figure 5). 
Ovophis VEGF 2 is the most heavily expressed VEGF in that venome, at $0.222 \%$ (Additional file 3: Table S2). Human VEGF-A binds to fms-like tyrosine kinase-1 (VEGF Receptor-1) (VEGFR-1) and to kinase insert domain-containing receptor (VEGFR-2), but not to VEGFR-3 (fms-like-tyrosine kinase-4) [95-98]. VEGF-A induces vasodilation mediated by nitric oxide [99] and increases vascular permeability 50,000-fold more potently than histamine [100]. In addition, VEGF-A promotes tachycardia, hypotension, and diminished cardiac output when injected

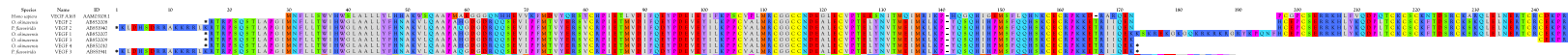

Figure 5 Alignment of VEGF sequences. Owing to the diversification of this toxin family, classification of venom VEGFs is difficult. Ovophis VEGF 1 [AB852007] possesses a 24-residue insert seen in no other sequence. Ovophis VEGF 5 [AB848274] and Protobothrops VEGF 1 [AB848141] are homologous to vammin, from the venom of Vipera ammodytes. All three of these display short C-terminal extensions of 16-17 residues that bind heparin [102]. Both vammin and VR-1, a VEGF from Daboia russellii venom, enhance vascular permeability with great potency. Another subclass of VEGF including Ovophis VEGF 3-4 [AB852009, AB852010] and Protobothrops VEGF 3 [AB851941] comprise a subclass with no C-terminal extension, or an extremely short extension corresponding to the C-terminus of Ovophis VEGF 1-2 [AB852007, AB852008] and Protobothrops VEGF 2 [AB851940]. These are significantly shorter than barietin, from the venom of Bitis arietans [98], and they do not align well with it or with vammin. 
i.v. in rats [101]. It is likely that Ovophis VEGF 1-2 and Protobothrops VEGF 2 have similar pharmacology, as these symptoms are consonant with snake envenomation strategies [1].

Ovophis VEGF 5 [AB848274] and Protobothrops VEGF 1 [AB848141] are homologous to vammin, from the venom of Vipera ammodytes. All three of these display short C-terminal extensions of 16-17 residues that bind heparin [102] (Figure 5). Vammin specifically recognizes VEGFR-2 [98]. Both vammin and VR-1, a VEGF from Daboia russellii venom, enhance vascular permeability with greater potency than does VEGF-A ${ }_{165}$ [98]. Additionally, Yamazaki et al. [103] have shown that a Lys-49 PLA 2 without catalytic activity further enhances the vascular-permeability promoting capacity of vammin.

Ovophis VEGF3-4 and Protobothrops VEGF3 comprise a subclass with no C-terminal extension, or an extremely short extension corresponding to the C-terminus of Ovophis VEGF 1-2 and Protobothrops VEGF2 (Figure 5). These are significantly shorter than barietin from the venom of Bitis arietans [98], and they do not align well with it or with vammin (Figure 5).

\section{5'-Nucleotidase}

Both transcriptomes included a single transcript for 5'nucleotidase (Additional file 1: Table S1 and Additional file 3: Table S2) [Pf: AB848147; Oo: AB851991]. In both transcriptomes 5'-nucleotidase was a negligible constituent. Mass spectrometry identified 51 venom peptides accounting for $63.3 \%$ of the expected sequence of the mature Protobothrops protein, while 65 unique peptides were detected in Ovophis venom, accounting for $12.9 \%$ of the 5 '-nucleotidase in that venom.

5'-nucleotidase is ubiquitous in snake venoms [104-107], suggesting a central role in envenomation. This enzyme is known to cleave a wide variety of ribose- and deoxyribosecontaining nucleotides [108-110]. It is most active against AMP $[109,110]$ supporting the central role of adenosine in envenomation proposed by Aird [1]. 5'-nucleotidase does not cleave flavin mononucleotide, or cAMP; however, these are hydrolyzed by venom PDE.

\section{Galactose-binding lectins}

In contrast to $\mathrm{C}$-type lectin-like proteins (CTL), galactosebinding lectins (GBLs) possess intact calcium and galactose-binding loops [72]. GBLs are similar in size to CTL-like proteins and are also dimeric. However, instead of interacting with platelets, GBLs aggregate erythrocytes $[111,112]$. For this reason, most authors, starting with Gartner et al. [112], have assumed that the presence of GBLs in venom is related to envenomation; however, several lines of evidence raise the possibility of a role unrelated to prey immobilization or digestion [1].
GBLs have been shown to be strongly mitogenic [113-115]. Their mitosis-inducing effects on lymphocytes were found to be comparable to those of concanavalin A [115]. Fry and Wüster [116] noted that GBLs appear to be basal phylogenetically among venomous snakes, whereas CTL-like proteins appear only in the Viperidae. Unlike CTL-like proteins, GBLs display very little sequence variability, suggesting that they are not under selective pressure to diversify, as CTL-like proteins are [117]. Lectins with similar sugar specificity are found in many tissues [118]. In Protobothrops and Ovophis, GBLs are expressed at very low levels (Additional file 1: Tables S1 and Additional file 3: Table S2) [Pf: AB848130; Oo: AB848277]. Ogilvie et al. [119] likewise found low expression levels for GBLs in Bothrops atrox $(0.2 \%)$ and Dendroaspis jamesonii (0.4\%) venoms, with a somewhat higher level (0.8\%) in Lachesis muta venom. Lomonte et al. [120] found that the GBL from Cerrophidion godmani venom exhibited edema-forming activity in mice, but concluded that with its low potency and low abundance, it probably plays relatively little role in envenomation. The aforementioned data suggest that GBLs may exist in venom as mitogens to regulate synthetic activity in the glandular epithelium itself. If this view is correct, hemagglutinating and edematogenic activities would be fortuitous, but of secondary importance. Nonetheless, the relative importance of such activities might vary among taxa.

\section{Aminopeptidases}

Aminopeptidase $\mathrm{N}$ plays a significant role in preventing hypertension by degrading Angiotensin III to Angiotensin IV [121]. The role of aminopeptidase A in blood pressure regulation appears to be more complex. APA degrades Angiotensin II to Angiotensin III [122]. When acting at peripheral sites, Angiotensin III is less potent hypertensive than Angiotensin II [122], but in central sites, Angiotensin III raises blood pressure more effectively than Angiotensin II $[122,123]$.

Various lines of evidence suggest a role for APA in promoting hypotension in situations analogous to envenomation. Systemic administration of APA in spontaneously hypertensive rats [124] or hypertensive rats infused with angiotensin II [125] reduced their blood pressure. Administration of amastatin, an APA inhibitor, raised blood pressure in normotensive rats [126].

To date nominal aminopeptidases $\mathrm{A}$ and $\mathrm{N}$ have been isolated from pit viper venoms, although expression levels appear to be generally low, and many venoms apparently may not contain either. In the present study, Ovophis venom contained a complete transcript for Aminopeptidase A [AB848288], while Protobothrops venom contained two APA transcripts [AB848148, AB848149]. However, the Ovophis Aminopeptidase A transcript comprised only 
$0.002 \%$ of all transcripts, while the two more abundant Protobothrops transcripts together comprised 0.073\%; hence both are very minor venom constituents. Ovophis APA and Protobothrops APA 1 were closely related to that reported from Gloydius brevicaudus venom [127], differing at only 24 and 22 residues out of 953 , respectively.

$\mathrm{Tu}$ and Toom [128] found that nearly all venoms hydrolyze L-leucyl- $\beta$-naphthylamide, but that there exists great variation in activity levels. Aird [1] suggested that the principal function of leucine aminopeptidase (arylamidase) (LAP) is digestive and that it links the hemorrhagic venom metalloproteases and other venom and endogenous prey peptidases, to L-amino acid oxidase in order to potentiate $\mathrm{H} 2 \mathrm{O} 2$ liberation, resulting in hypotension and anticoagulation. It is probable that numerous other amino- and carboxypeptidases in plasma also pass free amino acids to LAO. Clearly the release of Leu from circulating peptides is not solely dependent upon venom LAP. This may partly explain the variation in LAP levels that exists among different venoms [107]. If LAP is abundant in prey tissues, there may not be great selection pressure governing its level of expression in venoms. In the two transcriptomes, LAP was a very minor component [Pf: AB851938; Oo: AB851994] (Additional file 2: Table S4 and Additional file 4: Table S5).

The Protobothrops transcriptome possessed two aminopeptidases that show similarity to Aminopeptidase $\mathrm{N}$ [AB851954, AB851955] (Additional file 2: Table S4), but some of these did not manifest much similarity to the two Gloydius brevicaudus enzymes [127]. They also showed similarity to Aminopeptidase A, so without careful biochemical analyses it is impossible to classify them precisely. Furthermore, it may be that the aminopeptidase nomenclatural system devised for use with human enzymes, may not be applicable to snake venom aminopeptidases.

\section{Dipeptidyl peptidase IV}

Dipeptidyl Peptidase IV (DPP IV) was first discovered in venoms of various Micrurus species by Jorge da Silva and Aird [107]. It was also detected in the venoms of two other elapids, Bungarus multicinctus, Naja naja, and in that of the Brazilian crotaline, Bothrops moojeni. DPP IV titers varied by more than $4 \mathrm{x}$ among the different venoms. DPP IV is believed to function in envenomation by blunting a hypertensive response on the part of envenomated prey [1]. Ogawa et al. [129] published the first snake venom DPP IV primary structures, a pair of isomeric sequences derived from cDNA libraries of Gloydius brevicaudus venom glands. They determined that the signal peptide was not removed from these sequences. Later Ogawa et al. [130], showed that DPP IV, is actually secreted membranebound in exosomes. These micro-vesicles probably account for the "pre-peak" that elutes well ahead of the largest proteins when snake venoms are fractionated using gel filtration chromatography $[131,132]$. Exosomes were later shown to be present in human saliva as well [133]. DPP IV is nearly ubiquitous among elapid and viperid venoms, but it exhibits great quantitative variability even among full siblings [134].

The Protobothrops flavoviridis DPP IV sequence [AB851922] comprises 751 residues, like those from Gloydius, while the Ovophis sequence has 752 [AB848286]. Nonetheless, the Protobothrops and Ovophis sequences are more similar to each other than to the Gloydius sequences (Additional file 15: Figure S8). The Protobothrops sequence is missing one of a pair of asparagine residues present in the other three sequences, but both the Protobothrops and Ovophis sequences have a leucine residue that is missing in the Gloydius sequences (Additional file 15: Figure S8). No DPP IV peptides were discovered with mass spectrometry following enzymatic digestion of Protobothrops venom; however, three unique peptides accounting for $4.6 \%$ of the Ovophis DPP IV sequence were isolated. Venoms were well centrifuged before sample digestion, which probably pelleted the exosomes; thus it is surprising that any Ovophis peptides were identified.

\section{Glutaminyl cyclase}

QC cyclizes, and thereby protects the N-termini of biologically active peptides, such as the BPPs [135], some metalloproteases [136-138], and the $B$ and $C$ chains of the acidic subunit of crotoxin homologs $[139,140]$. No direct role in envenomation has been suggested for QC to date. However, while cyclization protects these peptides against degradation by prey plasma aminopeptidases, in the case of BPPs, bradykinin-potentiating potency is reduced by half [82].

A total of five snake venom QC cDNAs have been sequenced to date. Two of these belong to colubrids of the Genus Boiga [141] and the other three have been sequenced from crotalids on three different continents (Gloydius blomhoffii, Bothrops jararaca, and Crotalus adamanteus).

The present study adds eight additional sequences, of which a couple are distinctly different from those previously published. The Protobothrops sample contained four QC transcripts for two pairs of toxins [AB848133, AB848134, AB851933, AB851934]. The two identical long Protobothrops transcripts show near identity with other published crotalid sequences (Figure 6). However, as confirmed by the presence of stop codons, two other identical short sequences are missing the $\mathrm{N}$-terminal 37 residues of the longer sequences. The next eight residues of the short sequences are unique, but thereafter they are identical to the long sequences (Figure 6). Pawlak and Kini [141] reported a similar, though less extensive deletion in the Boiga dendrophila QC; thus it is clear that this sort of alternate splicing/post-translational modification 
Figure 6 Alignment of four Protobothrops and two Ovophis glutaminyl cyclase (QC) sequences with bovine QC and with sequences reported from two colubrid and three additional crotalid venoms. The two long Protobothrops transcripts [AB848133 and AB848134] show near identity with other crotalid sequences, except for an N-terminal 15 residues upstream of the N-terminal methionine. The short Protobothrops sequences [AB851933, AB851934] are missing the N-terminal 37 residues of the longer sequences. The next eight residues of the short sequences (QC 3-4) are unique, but thereafter they are identical to the long sequences. Ovophis venom also contains two QC [AB852014, AB852015] sequences, but owing to the lack of an N-terminal stop codon, no conclusions can be drawn regarding their length. Positions 18 and 47 differentiate Boiga from the crotalids. Positions 27, 294, 298, and 300 are variable across the different taxa.

is characteristic of snake venom QCs. Ovophis venom also contains four QC sequences [AB852014, AB852015, AB851985, AB851986], but because all are incomplete, no conclusions can be drawn regarding their length. The most highly expressed of these four represented only $0.008 \%$ of all transcripts (Additional file 3: Table S2), consistent with an indirect role in envenomation. Peptides were isolated for all four Protobothrops QCs, but only one of the Ovophis isoforms.

\section{Hyaluronidase}

Hyaluronidase is not a major constituent of either venom. A single complete transcript was found in the Protobothrops library [AB851937], while two complete Ovophis transcripts were sequenced [AB851977, AB851978]. No hyaluronidase transcript was more abundant than the cutoff for contaminants and no peptides were isolated from either venom. Venom hyaluronidase has been deemed a "spreading factor" because its degradation of the extracellular matrix enables other venom constituents, such as metalloproteases and phospholipases, to attack additional tissues [142,143]. As such, hyaluronidase probably serves primarily to digest the prey.

\section{Three-finger toxins}

Protobothrops venom, but apparently not that of Ovophis, contains a three-finger toxin (3FTx) [AB851958]. This sequence is most closely related to a transcript reported from Sistrurus catenatus edwardsi venom [144] and to candoxin isolated from the venom of an elapid, Bungarus candidus [145] (Figure 7). 3FTxs were not detected in an earlier study of Sistrurus catenatus barbouri venom [146], and they have not been observed in many other venomics studies of pit vipers [62,147-152]. Other studies have located 3FTxs by transcriptomic means, but not by proteomics approaches [15]. This is not surprising, given their low expression levels in many taxa $(0.8 \%$ in Sistrurus catenatus venom [144]). While 3FTxs are minor components of most pit viper venoms, relatively high expression levels have been reported in some species. In a study of Caribbean pit vipers, using Roche 454 sequencing technology, Durban et al. [32] reported considerable variability (Crotalus simus, $12.7 \%$, western Bothrops asper, 4.7\%; Bothriechis schlegelii, 3.6\%; eastern Bothrops asper,
0.8\%; Cerrophidion godmani, 0.6\%; and Atropoides picadoi, $0.4 \%)$.

The Protobothrops 3FTx differs slightly in its disulfide bond structure from all known 3FTxs (Figure 7). It shares a cysteine residue in position 18 with the 3FTx from Sistrurus catenatus edwardsi venom; however, Cys-11, which is linked to Cys-18 in the Sistrurus toxin, in the Deinagkistrodon acutus short neurotoxin, and in candoxin, occurs at position 9 in the Protobothrops toxin (Figure 7).

\section{Enzymes involved in purine and pyrimidine biosynthesis}

Aird [1] explained the neuromodulatory and hypotensive roles of purine nucleosides in the pharmacology of snake envenomation. A later study quantified purine and pyrimidine nucleosides in a wide variety of elapid, viperid, and crotalid venoms [31]. Possible roles of uridine and cytidine in envenomation are less clear than those of purine nucleosides. Because nucleosides are endogenous regulatory substances in all vertebrates, it is impossible for any prey species to develop resistance to them; thus they represent the perfect predatory biochemical weapon. However, their endogenous nature also means that the enzymes involved in nucleoside biosynthesis would be expected in any venom gland transcriptome, regardless of whether nucleosides are actually secreted into the venom in quantities relevant to envenomation. As a result, no venomics studies to date have specifically looked for the presence of nucleoside biosynthetic enzymes. Instead they have been treated as "housekeeping" genes. In fact, only Rokyta et al. [62] have reported the sequences of adenylosuccinate synthetase, adenylosuccinate lyase, IMP dehydrogenase, GMP synthetase, nucleoside monophosphate kinase, nucleoside diphosphate kinase, or CTP synthetase.

In both transcriptomes, we found transcripts for all four of the enzymes required to synthesize AMP and GMP from IMP [adenylosuccinate synthetase, Pf: AB851944; Oo: AB851992, AB851995; adenylosuccinate lyase, Pf: AB851928; Oo: AB851974; IMP Dehydrogenase, Pf: AB848116; Oo: AB851975, AB851979, AB852003; GMP synthetase, Pf: AB851932, AB851936, AB851946, AB851952; Oo: AB851972, AB851983, AB851999] (Additional file 1: Table S1 and Additional file 2: Table S4). The monophosphates may then be dephosphorylated by a variety of non-specific phosphatases or by venom or endogenous 


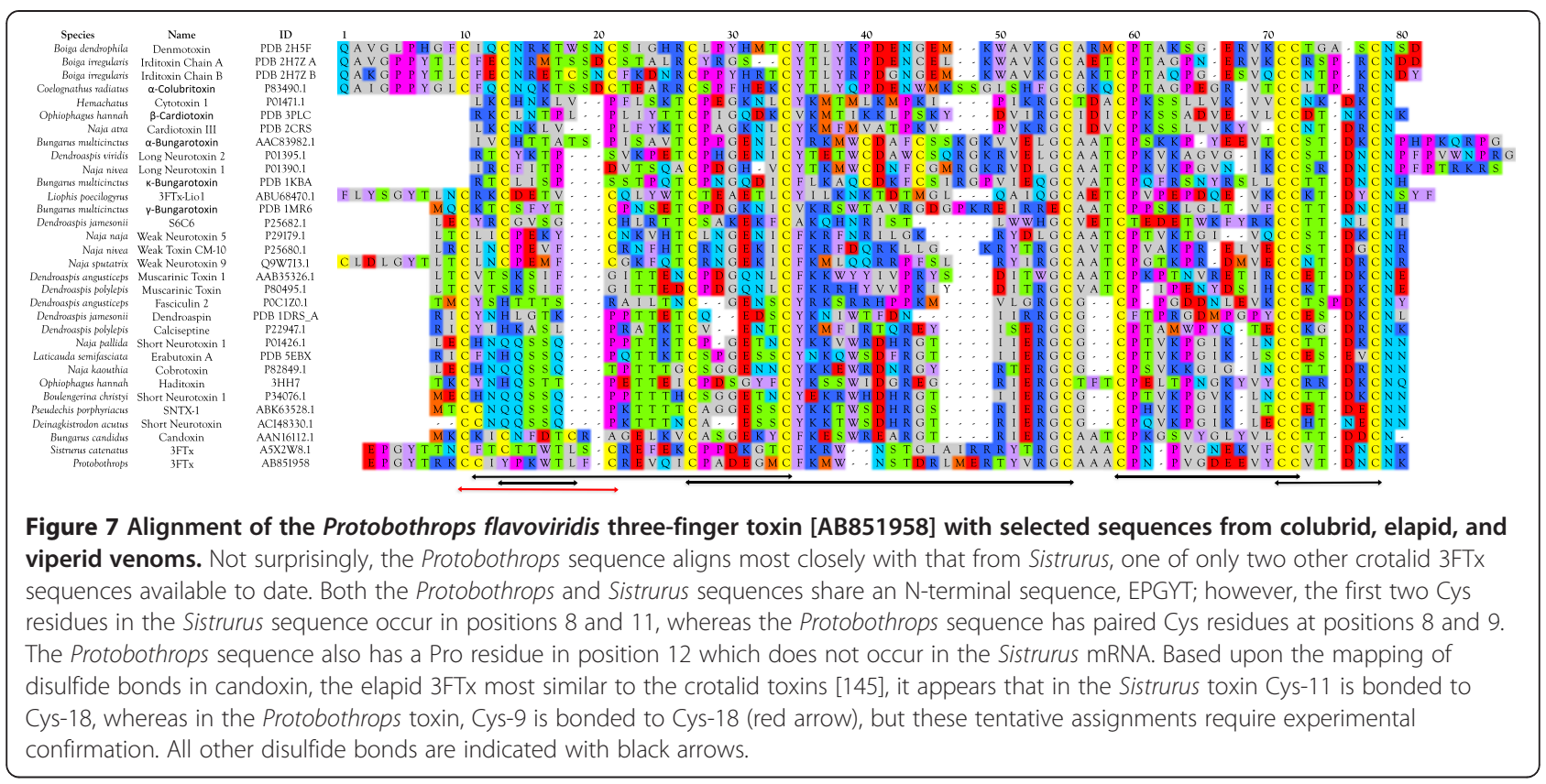

prey 5'-nucleotidase. Regarding pyrimidine biosynthetic enzymes, nucleoside diphosphate kinase [Pf: AB851920, AB851929; Oo: AB851996, AB852013] and CTP synthetase [Pf: AB851957, AB851927, AB851931; Oo: AB851984, AB851993] were found in both transcriptomes, but nucleoside monophosphate kinase was detected only in Protobothrops [AB851951](Additional file 2: Table S4). All of these sequences were identical or nearly so to those reported by Rokyta et al. [62,153].

Unfortunately, because both species in the present study are crotalids, the confirmation of nucleoside biosynthetic enzymes in the venome was less interesting than it might have been. The crotalid envenomation strategy involves liberation of endogenous prey purine nucleosides, but the venoms themselves have a minimal nucleoside content $[1,31]$. In contrast, some viperid venoms and mamba venoms may contain nearly $9 \%$ purines by dry weight [31]. Thus in crotalid venomes, nucleoside biosynthetic enzymes probably are largely metabolic in function. It would be interesting to examine the transcript levels of these enzymes in Bitis or Dendroaspis venoms by comparison. Direct analysis of venom nucleoside levels would be required to determine what level of mRNA expression corresponds to a departure from metabolic function to envenomation.

\section{Acid Phosphomonoesterase}

Acid PME comprised a negligible percentage of all transcripts in both venoms (Additional file 2: Table S4 and Additional file 4: Table S5) [Pf: AB851930; Oo: AB851982]. The sequences were most closely related to a tissue PME from Anolis carolinensis. To the best of our knowledge, these are the first snake acid PME mRNA sequences reported.

\section{Acetylcholinesterase}

The Ovophis transcriptome included five acetylcholinesterase (AChE) transcripts that collectively amounted to less than the contaminant cutoff for venom gland transcripts, so its presence in the transcriptome may be accidental (Additional file 4: Table S5) [AB852000, AB852001, AB852002, AB851981, AB851973]. AChE activity is considered characteristic of most elapid, but not viperid venoms. $\mathrm{AChE}$ transcripts have been reported recently in selected colubrid and dipsadid venoms $[11,154]$. These are the first reported crotalid transcripts.

\section{Homologs of crotamine, GAP and crotasin}

Crotamine, a highly basic 42-residue myotoxin was first reported 75 years ago [155] in the venom of Crotalus durissus terrificus. Homologs were later discovered in various other rattlesnake venoms [156-160]. These proteins display perplexing geographic distributional patterns [161] and individual quantitative variation [131], and they are products of duplicated loci [162]. Their physiological targets have remained controversial [163-169] and new biochemical activities continue to be discovered [170-176]. Myotoxin $a$, a crotamine homolog from the venom of Crotalus viridis viridis, was shown to undergo temperaturesensitive conformational transitions owing to cis-trans isomerization of Pro-20 [177,178]. It is unknown whether the isomers bind to different physiological targets.

Marquardt et al. [179] patented a crotamine homolog called GAP (growth arresting peptide) with mitosis-arresting 
activity. It was isolated from the venom of Crotalus atrox, which, to date, has not been reported to contain a small myotoxin. GAP seems to have gone unnoticed by the toxinological community for the past 24 years, but crotasin, a crotamine homolog with some of the structural features of GAP was reported by Radís-Baptista et al. [180].

The present study isolated two GAP/crotasin-like transcripts from the Ovophis transcriptome (Figure 8) [AB852005, AB852006], but no crotamine- or crotasin-like sequence was found in the Protobothrops transcriptome. Crotasin/GAP-like proteins are significantly less basic than the crotamine-like proteins, and they lack a Phe-Pro dipeptide (crotamine residues 12-13), as well as the N-terminal Tyr of the latter. The two Ovophis transcripts differ very significantly from each other and from both GAP and crotasin (Figure 8). Though the exact location of the $\mathrm{N}$-terminal residue cannot be determined with certainty, they both apparently possess the N-terminal disulfide bond present in crotamine and GAP, but absent in crotasin, and they are comparable in length to crotamine and GAP. Crotasin lacks the N-terminal eight residues of crotamine homologs. However, the signal peptide sequence for various crotamine isomers [181] exactly matches the signal peptide sequences of our Ovophis crotasin/GAP homologs. Both Ovophis transcripts manifested near-zero transcription levels, so it seems unlikely that these are functional venom components, but it is clear that the sequence diversification that Oguiura et al. [182] reported, applies to these transcripts as well.

\section{Waprins}

Waprins belong to a family of proteins with diverse activities that are structurally related to whey acidic protein [183]. Other members of the family have antibacterial activity and protease inhibitory activity [184,185]. Waprins discovered to date are small proteins of about 50 amino acids, containing four disulfide bonds [186]. Clauss et al. [187] identified a segment of human chromosome 20, displaying 14 genes for proteins related to whey acidic protein. They postulated that the resulting gene products could potentially serve an anti-microbial function against pathogenic bacteria, or that they might participate in the regulation of endogenous proteases. They also opined that kallikrein-like proteases are of particular interest.
The protease inhibitory capacity of members of this family suggests possible roles in envenomation, though to date, no evidence has been presented for any of these functions. Snake venom proteins belonging to the Kunitz/ BPTI family have been modified to serve as ion channel inhibitors [188] and to chaperone neurotoxic PLA $\mathrm{PL}_{2} \mathrm{~S}$ [189]. BPPs inhibit angiotensin I-converting enzyme to promote hypotension $[83,190]$, but also may act directly upon other physiological targets to induce hypotension [191,192]. Some of the bradykinin-potentiating peptides serve an interesting dual role by inhibiting hemorrhagic metalloproteases in the venom gland [193].

Pahari et al. [144] reported the first viperid waprin-like protein in the venom glands of Sistrurus catenatus edwardsi. However, the putative Sistrurus toxin comprised a waprin domain fused to a Kunitz/BPTI domain. The function of the encoded protein is unknown. It was represented by only a single transcript, so it is difficult to say whether this toxin is biologically significant. This nonenzymatic toxin was expressed at near-zero levels.

Rokyta et al. [62] reported a full-length waprin transcript in the venom of Crotalus adamanteus. Both the Protobothrops and Ovophis transcriptomes contained transcripts that were strongly homologous to the Crotalus waprin [Pf: AB851939; Oo: AB852011] (Figure 9). Interestingly, the Ovophis waprin has a C-terminal Pro-Met, instead of the usual Pro-Leu/Val-Pro. One peptide representing 28\% of the transcript sequence was isolated (Additional file 3 : Table S2).

Both venoms also contained sequences that are related to the Kunitz serine protease inhibitor domain of the novel ku-wap hybrid toxin from Sistrurus catenatus edwardsi venom [62] (Figure 9). All of these transcripts are incomplete and the three $\mathrm{N}$-terminal transcripts show relatively little overlap with the region of fusion in the Sistrurus ku-wap toxin; however, all three of the putative ku-wap homologs show the acidic and basic residues (positions 83-84) and other features of the Kunitz domain of the Sistrurus toxin (Figure 9). They do not show strong homology to either $\alpha$-dendrotoxin [194] or to bovine pancreatic trypsin inhibitor (Figure 9). They may be additional examples of the ku-wap family; however, they appear to be most closely related to vertebrate inhibitors of the tissue factor pathway. 


\section{Putative inhibitors of tissue factor pathway}

In vertebrates, blood coagulation is initiated by the tissue factor (TF) pathway. This pathway is regulated primarily by tissue factor pathway inhibitor (TFPI), a Kunitz serine protease inhibitor that inhibits Factor Xa and thrombin at concentrations as low as $2.5 \mathrm{nM}$, thus controlling the generation of thrombin and ultimately, of fibrin $[195,196]$. Platelet TFPI is believed to modulate intravascular coagulation [197].

The Protobothrops transcriptome contained a single, partial transcript [AB851921] and the Ovophis transcriptome contained two, very short, identical transcripts [AB851997, AB851998] that align well with a predicted Anolis TFPI, and less well with the Ku-Wap fusion toxin from Sistrurus catenatus edwardsi venom glands and with bovine pancreatic trypsin inhibitor (Figure 10; Additional file 2: Table S4 and Additional file 4: Table S5). The Protobothrops TFPI transcript aligns well with both the acidic N-terminus and the highly basic C-terminus of human TFPI $[198]$ (Figure 10).

All three transcripts are expressed at vanishingly low levels ( $\sim 0.001 \%$ of all transcripts) and it seems extremely unlikely that they function in envenomation; however, peptides ranging from $6.3 \%$ to $11.9 \%$ of the Protobothrops and Ovophis sequences were isolated. Most likely, these are tissue transcripts related to snake vascular homeostasis. If they serve any additional roles, they might inhibit venom SPs in the gland, or they might inhibit prey thrombin, allowing venom SPs to clot fibrinogen improperly, resulting in its rapid clearance by the prey's anti-clotting cascade.

\section{Paraoxonase}

Paraoxon hydrolytic activity has been reported only in the venom of Daboia russellii to date [199]. Venoms of Naja naja, Crotalus adamanteus, and Agkistrodon contortrix contortrix showed only trace level activity by comparison. Three genes comprise the paraoxonase gene family in humans. PON1 is largely associated with high-density lipoprotein, but has organophosphatase, arylesterase, or lactonase activities, and it hydrolyzes a wide array of substrates [200]. PON2 and PON3 are not well studied, but PON2 is known to be a widely-distributed cellular enzyme. Two transcripts were found in the Protobothrops transcriptome, but none in Ovophis. Both Protobothrops transcripts were expressed at near-zero levels, suggesting that paraoxonase is not a venom component in either of these species. The Protobothrops paraoxonase isozymes share diagnostic residues with all three human isozymes and are not clearly related to any one of them [AB851924, AB851925].

\section{Vespryns}

Pung et al. [201] isolated a novel $12 \mathrm{kDa}$ toxin from the venom of the king cobra that acts centrally to induce hypolocomotion and pain in mammalian prey. A toxin from Lachesis muta venom [202] was the first crotalid vespryn and a second was sequenced from Crotalus adamanteus venom [62]. The Protobothrops transcriptome contained a partial, 70-residue vespryn transcript [AB851949], but the Ovophis transcriptome had none (Additional file 16: Figure S9). No vespryn peptides were sequenced. The Protobothrops vespryn is most closely related to that from Lachesis, which also displays a four-residue gap from positions $25-28$. Only three of the first 70 residues differ between these two toxins. The three crotalid vespryns are all 28-32 residues longer at the $\mathrm{N}$-terminus than the two corresponding toxins from Ophiophagus hannah and Pseudechis australis venoms [203].

\section{Conclusions}

Using two distantly related pit viper species with different venom compositions, our study illustrates the power of using next generation sequencing in combination with LC/MS profiling for the study of venom chemistry. We were able to detect a wide variety of venom components in both cDNA and in the venom itself. Except for the annotation of protein function, the analytic pipeline was entirely self-contained and did not rely on publicly available reference databases. Given the decreasing costs of sequencing, and the increasing power of mass spectrometry, this approach will be increasingly useful for

蕉

Figure 10 Alignment of TFPI-like sequences. The putative Protobothrops TFPI transcript [AB851921] is most similar to a DNA sequence from Anolis carolinensis. It aligns best at the C-terminus and in the middle, except for a 27-residue deletion in the Protobothrops sequence, which separates these two regions. Two partial transcripts from Ovophis venom glands [AB851997, AB851998] are identical to that from Protobothrops in the middle section. Affinities of these toxins to bovine pancreatic trypsin inhibitor and to the Ku-Wap fusion toxin from Sistrurus catenatus edwardsi venom are weak. 
poorly studied species that have no previously published reference data, and also for detecting fundamentally new venom components that might have been missed by earlier investigations.

We show, for the first time, that the composition of venom gland mRNA is linearly correlated with protein composition of the venom. Although this finding is fairly trivial by itself, especially given the amount of unexplained variance observed in our correlation, it has several interesting methodological implications. It appears that peptide detection with LC/MS can potentially be used to quantify individual proteins in venoms. This can allow highthroughput screening of numerous venom samples providing comparative data on the abundance of various components. Although probably not as sensitive or quantitative as cDNA sequencing, at least without further refinement, this approach permits non-invasive sampling, which will be important for rare or endangered species. Crude venom is also easier to collect and store than RNA, making it possible to collect numerous samples in the field, or to use archived venom samples. We are currently conducting studies focused on improving the accuracy of LC/MS-based venom peptide sampling and quantification, and on developing better metrics.

We obtained similarly quantitative results using de novo assembled transcriptomes and publicly available data from NCBI for protein identification (Additional file 8: Figure S1). This finding makes mass spectrometry useful even for species without custom-made species-specific reference transcriptomes. Although using publicly available data prevents the discovery of novel proteins, public data should be particularly useful for comparative studies, and for investigation of snakes for which transcriptomes cannot be obtained for whatever reason.

With regard to the utility of using mass spectrometry for non-invasive, quantitative sampling, another pair of studies report the isolation of intact mRNA directly from venoms $[204,205]$. It remains to be seen how quantitative this technique will prove to be and how useful it will be for archival samples, especially those that have been repeatedly frozen and thawed, but certainly it offers exciting possibilities, especially in combination with mass spectrometry.

The present study reports 103 venom or venom-related cDNA sequences from the venom glands of Protobothrops flavoviridis. Of these, 40 were previously known from the literature, although this figure includes isomeric forms not previously reported. Fifty-one sequences were similar to those reported from other venomous snake taxa, but were new for Protobothrops. An additional 12 have not previously been reported for any snake. In regard to Ovophis okinavensis, 94 of the $95 \mathrm{cDNA}$ sequences reported herein are new for this species, and 13 have not been reported previously for any snake. Peptides were sequenced from $100 \%$ of transcripts that were more abundant than contaminants such as human keratin (Additional file 1: Table S1 and Additional file 3: Table S2). Peptides were also sequenced from at least 18 additional transcripts that occurred below the contaminant level.

To the best of our knowledge this study also furnishes the first peptidyl sequence data (peptides sequenced by mass spectrometry) for venom phospholipase B and 5'-nucleotidase, and the first mRNA sequence data for a snake acid PME, adenylosuccinate synthase, paraoxonase, and a putative tissue factor pathway inhibitor. Novel crotasin/growth-arresting peptide/crotamine-like sequences are reported from the Ovophis transcriptome. The Protobothrops 3FTx sequence is only the third such sequence reported from a crotalid, but it differs in significant ways from the other two sequences.

Dominated by PLA 2 , MPs, and LAO, adult Protobothrops venom strategically promotes hemorrhage, hypotension, incoagulable blood, and prey digestion, consistent with mammalian predation. Ovophis venom, by contrast, is composed principally of SPs and MPs (93.1\% of all transcripts) (Figure 1; Additional file 1: Tables S1, Additional file 3: Table S2, Additional file 5: Table S3). Its composition is less readily interpreted, owing to inadequate pharmacological data for venom proteases. This venom apparently represents a hybrid strategy optimized for frogs and small mammals, but the contributions of most components cannot be unambiguously assessed at present.

\section{Methods}

\section{Venom and reagents}

Venom was extracted from one Protobothrops flavoviridis and one Ovophis okinavensis at the Okinawa Institute of Health and Environment. Four days later, venom glands were excised from each specimen. Prior to gland removal, the two snakes were anesthetized with chloroform until they showed no righting reflex or tail-retraction reflex. In pit vipers, the tail is always the last part of the body to become anesthetized and the first to recover from anesthesia. This euthanasia protocol complies with the "Guidelines for Proper Conduct of Animal Experiments" (Science Council of Japan, June 1, 2006).

Once the snakes were completely anesthetized, glands and underlying skeletal muscle were quickly excised after dissecting back the overlying skin. Each gland was immediately placed into a pre-labelled $1.5 \mathrm{~mL}$ microcentrifuge tube having a screw cap and an O-ring, and dropped into liquid nitrogen. Samples were then stored at $-80^{\circ} \mathrm{C}$ until the following week.

\section{Isolation of total mRNA from venom glands}

Total mRNA isolation employed a Qiagen RNeasy Plus Mini Kit and utilized the following procedure. Glands were removed from storage and their masses were determined 
without allowing them to thaw. Glands were immediately dropped into a $50 \mathrm{~mL}$ Falcon tube containing $3 \mathrm{~mL}$ of Buffer RLT Plus containing 1\% $\beta$-mercaptoethanol. Additional buffer was added after homogenization was begun. Ideally $600 \mu \mathrm{L}$ of buffer should be used for every $30 \mathrm{mg}$ of tissue. Accordingly, the $350 \mathrm{mg}$ Protobothrops gland was homogenized in $6.5 \mathrm{~mL}$ RLT buffer, but because the Ovophis gland weighed just $100 \mathrm{mg}$, only $2 \mathrm{~mL}$ were needed, but in the interest of prompt homogenization, $3 \mathrm{~mL}$ were used anyway.

Lysates were centrifuged 3 min at maximum speed and $600 \mu \mathrm{L}$ were transferred to each of five gDNA Eliminator spin columns. All ten samples were then processed according to Qiagen's instructions. Eluents from the five tubes were pooled for each of the samples.

Next the Ambion LiCl RNA precipitation technique was employed, after reserving $50 \mu \mathrm{L}$ of each pool for analysis on the Nanodrop ND-1000. Pellets were resuspended $10 \mathrm{mM}$ Tris, $1 \mathrm{mM}$ EDTA.

All four samples were diluted to bring them into the 25-500 ng/ $\mu \mathrm{L}$ range for analysis on an Agilent Bioanalyzer 2100 using an RNA Nano 6000 chip. The pre-LiCl Protobothrops sample had an RNA Integrity Number (RIN) of 9.5, while the other three samples were all 10.0.

\section{cDNA synthesis and preparation of Illumina RNA-Seq libraries with barcodes}

Post- $\mathrm{LiCl}$ samples were used for first strand cDNA synthesis. In $200 \mu \mathrm{L}$ PCR tubes, $1 \mu \mathrm{L}$ of each total RNA sample was combined with $3 \mu \mathrm{L}$ water and $1 \mu \mathrm{L}$ of $10 \mu \mathrm{M}$ CapTRSA-CV primer (AAGCAGTGGTATCAACGCAGAGT CGCAGTCGGTACTTTTTTCTTTTTTV). Samples were incubated $3 \mathrm{~min}$ at $65^{\circ} \mathrm{C}$, and then chilled on ice. Total RNA concentrations for the Protobothrops and Ovophis samples were 1,282 and $930 \mathrm{ng} / \mu \mathrm{L}$, respectively.

Next the following were added to each tube: $2.0 \mu \mathrm{L} 5 \mathrm{x}$ first-strand synthesis buffer (Clontech ST0079), $0.5 \mu \mathrm{L}$ $10 \mathrm{mM}$ dNTP (Clontech ST0073), $1.0 \mu \mathrm{L} 0.1 \mathrm{M}$ DTT (Invitrogen Y00147), $1.0 \mu \mathrm{L} 10 \mu \mathrm{M}$ template-switch primer (RNA oligo Smarter IIA, Clontech ST0069), and $1 \mu \mathrm{L}$ Superscript II reverse transcriptase (Invitrogen). Tubes were incubated $1 \mathrm{hr}$ at $42^{\circ} \mathrm{C}$. Reactions were terminated by heating at $65^{\circ} \mathrm{C}$ for $15 \mathrm{~min}$. Tubes were then placed on ice and samples were diluted with $40 \mu \mathrm{L}$ water prior to cDNA amplification.

Eight tubes of each first-strand cDNA were prepared for second-strand synthesis and amplification using an 8.5x master mix containing: $25.5 \mu \mathrm{L}$ first-strand cDNA, $178.5 \mu \mathrm{L}$ water, $25.5 \mu \mathrm{L}$ 10x PCR buffer (10x Advantage 2 SA PCR Buffer (S3245), $6.375 \mu \mathrm{L} 10 \mathrm{mM}$ dNTP, $11.9 \mu \mathrm{L}$ cDNA Amplification primers (Clontech Nested Universal primer A, ST0102), and $5.1 \mu \mathrm{L}$ Advantage 2 polymerase (Clontech).
Using a thermocycler, samples were heated to $95^{\circ} \mathrm{C}$ for $1 \mathrm{~min}$. This was followed by 11 cycles of $\left(95^{\circ} \mathrm{C}\right.$ for $10 \mathrm{sec} / 68^{\circ} \mathrm{C}$ for $\left.6 \mathrm{~min}\right)$. Then the temperature was reduced to $72^{\circ} \mathrm{C}$ for $10 \mathrm{~min}$, before cooling to $4^{\circ} \mathrm{C}$. PCR products were purified with a QIAquick PCR purification kit (Qiagen). Products were analyzed on a Nanodrop ND-1000 to determine double-stranded cDNA concentrations.

Eight $\mu \mathrm{L}$ of each purified sample were loaded into a $1 \%$ agarose gel and electrophoresis was performed in $1 \mathrm{x}$ sodium borate buffer (56.6 mM Boric acid, $\mathrm{pH} 7.5$ adjusted with $\mathrm{NaOH}$ ) at $100 \mathrm{~V}$ for $30 \mathrm{~min}$. New England Biolabs 2-log DNA Ladder $(0.25 \mu \mathrm{L})$ was used to estimate DNA size.

Tagmentation followed the Epicentre Nextera DNA Sample Prep Kit (Illumina-compatible) protocol in a one-third size $(6.7 \mu \mathrm{L})$ reaction volume. The following components were assembled on ice: $4.2 \mu \mathrm{L}$ and $4.65 \mu \mathrm{L}$ nucleasefree water (for the Protobothrops and Ovophis samples, respectively), $16.7 \mathrm{ng}$ target DNA in $10 \mathrm{mM}$ Tris- $\mathrm{HCl}$ ( $\mathrm{pH} 7.5$ ) with $1 \mathrm{mM}$ EDTA, $1.35 \mu \mathrm{L} 5 \mathrm{X}$ Nextera reaction buffer HMW, $0.35 \mu \mathrm{L}$ Nextera enzyme mix (Illuminacompatible). The above reaction mixture was briefly vortexed, and incubated at $55^{\circ} \mathrm{C}$ for $5 \mathrm{~min}$ in an MJ Research PTC-200 peltier thermocycler with a heated lid. Tagmented DNA was purified using the Qiagen Min Elute protocol. We used Buffer ERC in the MinElute Reaction Cleanup Kit because it efficiently binds double-stranded DNA $\geq 70$ bp and removes enzymes, salts, and oligomers. The final step was to add DNA barcodes and to enrich the library following the Epicentre Nextera DNA Sample Prep Kit (Illumina-compatible) protocol.

\section{Sequencing and bioinformatics}

Both libraries were sequenced in a single Illumina GAII lane using 75-bp paired-end reads at OIST's sequencing center, according to the manufacturer's specifications. After quality filtering with Condetri (v. 2.0) [206] using the default setting, the reads were assembled using the Trinity RNA-seq suite [207,208]. FPKM values for the isoforms were computed using the RSEM package [209] included with Trinity. Using a threshold recommended by Mortazavi et al. [210], we filtered low abundance transcripts with FPKM less than 1, and used these as reference sequences for the proteomic pipeline.

\section{Reduction, alkylation, and digestion of venoms with trypsin and chymotrypsin}

Crude venom was centrifuged $10 \mathrm{~min}$ at maximum speed (20,238 rcf). Reactions were performed in $200 \mu \mathrm{L}$ PCR tubes. Reduction was accomplished using a reaction mixture that contained $37 \mu \mathrm{L}$ ultrapure water, $1 \mu \mathrm{L}$ venom (200-300 $\mu \mathrm{g}$ protein), $2 \mu \mathrm{L} 500 \mathrm{mM}$ DTT in ultrapure water, and $10 \mu \mathrm{L} 500 \mathrm{mM}$ Tris- $\mathrm{HCl}(\mathrm{pH} \mathrm{8.0)}$. Tubes were incubated $45 \mathrm{~min}$ at $60^{\circ} \mathrm{C}$ in the dark in a thermocycler. 
Following venom protein reduction, $10 \mu \mathrm{L}(0.38 \mathrm{mg})$ of iodoacetic acid $\mathrm{Na}^{+}$salt (Nacalai 19305-24) in ultrapure water were added to each tube and mixed with pipetting and gentle vortexing. Tubes were incubated $30 \mathrm{~min}$ at $37^{\circ} \mathrm{C}$ in the dark. Then $1 \mu \mathrm{L}$ of $500 \mathrm{mM}$ DTT was added to quench the alkylation reaction. Next $4.5 \mu \mathrm{L}$ of $200 \mathrm{mM}$ $\mathrm{CaCl}_{2}$ (Nacalai 06731-05) were added to each tube. An additional $5 \mu \mathrm{L}$ of $500 \mathrm{mM}$ Tris- $\mathrm{HCl}(\mathrm{pH}$ 8.0) were added to maintain the $\mathrm{pH}$ and ionic strength. Finally, $10 \mu \mathrm{g}$ of trypsin (Pierce 90055) or chymotrypsin (Pierce 90056) dissolved in $1 \mathrm{mM} \mathrm{HCl}$ were added to each tube. Tubes were incubated $24 \mathrm{~h}$ at $37^{\circ} \mathrm{C}$ and then frozen at $-30^{\circ} \mathrm{C}$ until preparation for mass spectrometry.

\section{Digestion of venoms with Glu-C}

Reduction and alkylation of venoms were performed as described above, except that instead of $500 \mathrm{mM}$ Tris- $\mathrm{HCl}$, $167 \mathrm{mM}$ phosphoric acid/ $\mathrm{NaOH}(\mathrm{pH}$ 8.0) was used. Furthermore, the enzyme was dissolved in ultrapure water, rather than in $1 \mathrm{mM} \mathrm{HCl}$. This enabled the enzyme to cleave proteins adjacent to aspartic acid residues, as well as glutamate residues. When the enzyme was dissolved in $1 \mathrm{mM} \mathrm{HCl}$, it cleaved next to glutamate residues only, despite the use of phosphate buffers for hydrolysis.

Unlike trypsin and chymotrypsin, Glu-C (Pierce 90054) was inhibited by iodoacetate. It was necessary to desalt the reaction mixture before enzymatic digestion. Desalting was accomplished using Zeba Spin Desalting Columns (0.5 mL, Pierce 89882). Because naturally-occurring small peptides in venoms, such as bradykinin-potentiating peptides are removed by these spin columns, samples of crude venoms were also prepared for direct analysis by mass spectrometry, after removal of large proteins.

\section{NanoLC-mass spectrometric analysis}

A Thermo Scientific LTQ Orbitrap hybrid mass spectrometer was used for MS data collection. The mass spectrometer was equipped with an HPLC (Paradigm MS4, Michrom Bioresources, Inc.), an autosampler (HTC PAL, CTC Analytics) and a nanoelectrospray ion source. Each venom digest was desalted using a ZipTip $\mathrm{C}_{18} / \mathrm{P} 10$ (Millipore) prior to the NanoLC-MS run. Clean sample was separated on a capillary reverse phase column $(50 \times$ $0.15 \mathrm{~mm}, 3 \mu \mathrm{m}, \mathrm{MS} \mathrm{C}_{18}$, Grace Vydac). A one-hour gradient $(10 \% \mathrm{~B}$ to $30 \% \mathrm{~B}$ in $60 \mathrm{~min}$, where solvent $\mathrm{A}$ is $2 \%$ acetonitrile and $0.1 \%$ formic acid, and solvent B is $98 \%$ acetonitrile and $0.1 \%$ formic acid, flow rate $2.0 \mu \mathrm{L} / \mathrm{min}$ ) was used for the peptide separation. The temperature of the heated capillary was $200^{\circ} \mathrm{C}$, and $1.70 \mathrm{kV}$ spray voltage was applied to all samples. The mass spectrometer's settings were, full MS scan range 350 to $1500 \mathrm{~m} / \mathrm{z}$, with mass resolution of 60,000 at $400 \mathrm{~m} / \mathrm{z}, 50 \mu \mathrm{s}$ scan time with accumulation of three microscans. The three most intense ions from this full MS scan were fragmented in data-dependent manner with CID, using an exclusion list of 500 ions during 30 seconds. Triplicate NanoLC-MS analyses were run for every venom digest sample.

\section{Protein Identification}

Analysis of mass spectrometric data was performed using three different search engines: Mascot (version 2.4), Proteome Discoverer (version 1.2) and PEAKS (version 4.2 SP 1). Fragmentation spectra were filtered using Proteome Discoverer, allowing only double to quadruply charged ions, and removing the precursor ion within a window of $1 \mathrm{Da}$. Processed spectra were searched using Sequest and Mascot. Two missed cleavages were allowed, and precursor and fragment mass tolerance were set to $20 \mathrm{ppm}$ and $0.8 \mathrm{Da}$, respectively. Carboxyamidomethylation of cysteine was set as a fixed modification, while methionine oxidation and asparagine and glutamine deamidation were set as variable modifications. Enzymes used for sequencing (trypsin, R and K; chymotrypsin, F, L,W, and Y; Glu-C, D and $\mathrm{E}$ ) were specified in each case. For naturally occurring peptides (undigested venom samples), no enzyme was specified in the search. A constructed database, using the six possible frames for each detected transcript, with the common Repository of Adventitious Proteins - cRAP (http://www.thegpm.org/crap/) was used for both search algorithms (Protobothrops plus cRAP $=20,945$ entries; Ovophis plus cRAP $=15,264$ entries). Protein and peptide identifications from Mascot and Sequest results were combined, setting the false discovery rate to $1 \%$.

Spectra not identified were submitted for de-novo sequencing using PEAKS. Search parameters were the same as defined for Mascot and Sequest, except for specifying the mass spectrometer as an FT-trap, and allowing $\leq 3$ modifications per peptide. Results were filtered to allow only sequences with rank equal to zero and a PEAKS score higher than 20. These sequences were BLASTed against our constructed databases, and filtered, allowing only matches with an E score $<0.05$.

Combined results of all three search engines were used to report protein and peptide identifications. The same search (using Mascot and Sequest only) was performed using the NCBI database, subset for snake taxonomy (txid8570; 40,887 sequences).

\section{RNA-seq and proteomic comparisons}

Because longer transcripts produce more fragments, RNA-seq data are typically analyzed using metrics which standardize the number of reads mapped to a particular exon by the total number of mapped reads and the size of the exon [210]. We attempted an analogous measure of protein abundance based on peptides, to prevent longer proteins from appearing more abundant than they are. Unlike mRNA reads, each of which competes for a position in the flow cell, with adequate chromatographic 
separation, peptides are detected sequentially during their elution from the liquid chromatograph, and should be detected independently of one another. Under this assumption, we did not standardize by the total number of detected fragments. For each protein identified, we counted the total number of peptide fragments. Then we divided this number by the length of the protein to standardize for size, producing a measure of peptides per unit length of protein, which could then be correlated with the FPKM metric, computed as described above. The count of each peptide mapping to different proteins was divided by the number of matches, to account for mapping uncertainty.

To evaluate the robustness of our analysis relative to the reference protein data set chosen, a separate analysis was conducted using snake venom proteins from the publicly available NCBI database, for protein identification. This analysis was conducted as described above, except that that PEAKS identification was omitted in the interest of time. We used reciprocal best BLAST as the criterion for establishing homology between NCBI data and the de novo sequenced transcriptomes. This was a conservative choice, since many isoforms or closely related genes could generally have just one NCBI best hit.

The cRAP protein database, which lists common contaminants, was used to determine abundance thresholds for including predicted proteins. To determine this cutoff, we bootstrapped the $99.9 \%$ confidence intervals around the abundance scores for human contaminant proteins, which were most likely introduced during sample preparation, and which should be present at much lower concentrations than target proteins. Proteins below this threshold were filtered from the analysis.

\section{Additional files}

Additional file 1: Table S1. Abundance of individual toxin transcripts in the Protobothrops flavoviridis transcriptome, as RNA Fragments/Kilobase of Transcript Sequence/Million Base Pairs Sequenced (FPKM), arranged by toxin class. Transcripts that were less abundant than contaminant levels (e.g. human keratin) were not included in this table, even in cases in which peptides corresponding to those transcripts were isolated. Transcripts in blue are complete while those in yellow are incomplete. All significant venom constituents were identified by mass spectrometry. The number of amino acid residues and the percent coverage of the predicted protein by sequenced peptides are also shown. The expected protein length was determined from the transcript length minus untranslated regions and the putative signal peptide, if any.

Additional file 2: Table S4. Protobothrops flavoviridis transcripts that had negligible FPKMs. Incomplete transcripts are highlighted in yellow; complete transcripts are shown in blue. Peptide coverage data are presented for those transcripts with sequenced peptides. There is a high degree of certainty associated with all sequences except those highlighted in gray, although they may also be valid.

Additional file 3: Table S2. Abundance of individual toxin transcripts in the Ovophis okinavensis transcriptome, as RNA Fragments/Kilobase of Transcript Sequence/Million Base Pairs Sequenced (FPKM), arranged by toxin class. Transcripts that were less abundant than contaminant levels (e.g. human keratin) were not included in this table, even in cases in which peptides corresponding to those transcripts were isolated. Transcripts in blue are complete while those in yellow are incomplete. All significant venom constituents were identified by mass spectrometry. The number of amino acid residues and the percent coverage of the predicted protein by sequenced peptides are also shown. The expected protein length was determined from the transcript length minus untranslated regions and the putative signal peptide, if any. ${ }^{*}$ n the Ovophis transcriptome, an incomplete transcript for bradykinin-potentiating peptides and C-type natriuretic peptides was isolated. A single peptide was sequenced by mass spectrometry, but based upon a BLAST search, it originated in the missing portion of our transcript; hence coverage is given as $0 \%$.

Additional file 4: Table S5. Ovophis okinavensis transcripts that had negligible FPKMs. Incomplete transcripts are highlighted in yellow; complete transcripts are shown in blue. Peptide coverage data are presented for those transcripts with sequenced peptides. There is a high degree of certainty associated with all sequences except those highlighted in gray, although they may also be valid. ***One peptide (RPPGPPIPP) and two derivatives of the Ovophis BPP sequence were sequenced by mass spectrometry. This sequence does not occur in our truncated transcript, so no percent coverage is given; however, it is nearly identical to a proposed BPP from the N-terminal end of a BPP-CNP transcript from Gloydius blomhoffii (RPPGPPIPR) [78,81] and from Bothrops jararaca venoms [80].

Additional file 5: Table S3. Abundance of venom protein transcripts by toxin class in Protobothrops flavoviridis and Ovophis okinavensis venoms. The different envenomation strategies employed by these two pit vipers differ significantly, as illustrated especially by expression levels of MPs, PLA $A_{2}$, SPS, and CRISPS. Color fills indicate primary functions of toxin classes; however, many venom components have direct or indirect secondary and even tertiary functions. Yellow: Neurotoxic; Pink: Hypotensive; Blue: Anticoagulant; Green: Digestive. Some toxin functions are strategically counterintuitive. For example, thrombin-like SPs are directly pro-coagulant, but by activating the prey fibrinolytic system, their ultimate effect is anticoagulant.

Additional file 6: Table S6. Peptide coverage of non-venom-related transcripts from the cDNA libraries of Protobothrops flavoviridis venom glands. "Adjusted Counts" were used to discount peptides that matched multiple proteins, so as to avoid spuriously high values. Adjusted counts were used to create Figure 2 and Additional file 8: Figure S1.

Additional file 7: Table S7. Peptide coverage of non-venom-related transcripts from the cDNA libraries of Ovophis okinavensis venom glands. "Adjusted Counts" were used to discount peptides that matched multiple proteins, so as to avoid spuriously high values. Adjusted counts were used to create Figure 2 and Additional file 8: Figure S1.

Additional file 8: Figure S1. Correlation between abundances of proteins predicted using NCBI data (black) and de novo assembled reference sequence (grey). Homologies between the two protein sets were determined using reciprocal best BLAST, so many of the proteins detected in the de novo transcriptome were omitted in the comparison, because they did either did not have homology to known snake proteins, or this relationship could not be determined with certainty, e.g., in the case of multiple isoforms or closely related genes. Nonetheless, the correlation coefficients were close between the two data sets, suggesting that the measure of protein abundance was robust to the choice of protein reference data set (Protobothrops: NCBI $r=0.52, p=0.014$, Trinity $r=0.64, p=2.2 e^{-16} ;$ Ovophis: NCBI $r=0.64, p=1.2 e^{-4}$, Trinity $r=0.68$, $\left.p=6.3 e^{-10}\right)$. Note that the correlation coefficients differ slightly with Figure 2, since the analysis presented in Additional file 8: Figure S1 did not involve assignment of unmapped proteins by PEAKS

Additional file 9: Figure S2. Alignment of metalloproteases from the Protobothrops flavoviridis transcriptome. These sequences assort into two distinct groups, upper and lower. Members of the lower group display significant similarities and align well. Members of the upper group, for the most part, align poorly with one another, and essentially not at all with the lower group. Both groups contain both P-II and P-III MPs. Given the size of many MPs, some of these partial sequences probably represent non-overlapping segments, despite attempts by the software to align them. 
Additional file 10: Figure S3. Alignment of metalloproteases from the Ovophis okinavensis transcriptome, showing the sequences of five P-II and three P-III MPs.

Additional file 11: Figure S4. Alignment of 18 serine protease sequences from the Protobothrops flavoviridis transcriptome. SP12 appears to be an inactive plasminogen activator transcript, while SP11 is probably a truncated member of the same subclass.

Additional file 12: Figure S5. Alignment of 26 Orophis okinavensis serine protease sequences. It is impossible to infer biological activities from these transcripts; however, the Ovophis transcripts seem to fall into three or four structural subclasses or groupings. SP15 and related sequences with clusters of three acidic residues (positions 121-123) and three aromatic residues (position 132-134) appear most similar to thrombin-like enzymes. SP05 and 06 all display a high percentage of aliphatic and aromatic residues (positions 116-140), but their biological activity is not known. SP08 is apparently a thrombin-like enzyme. SP09 is most similar, based on this fragment, to an SP from Protobothrops jerdonit venom that has lost two of the three catalytic residues of active SPs.

Additional file 13: Figure S6. Alignment of all CTL transcripts from both venoms with sequences of convulxin (Crotalus durissus terrificus) and flavocetin (Protobothrops flavoviridis). Protobothrops venom contained various Factor IX/X binding proteins that were absent in Ovophis venom.

Additional file 14: Figure S7. Alignment of known bradykinin-potentiating peptides from various viperid venoms showing the great sequence variability in this toxin class [78-83,191,211-222].

Additional file 15: Figure S8. Alignment of Protobothrops flavoviridis [AB851922] and Ovophis okinavensis [AB848286] dipeptidyl peptidase IV sequences with two isomers from Gloydius brevicaudus venom. The former sequences each possess a leucine residue in position 268 that is missing in the Gloydius sequences. They also have Gly-80 where Gloydius has Glu, lle-85/Nal, Asn-113/Ser, Thr-170/Ala, Ser-215/Arg, Ala-395/Ser, Arg-502/Ser, Gly-632/Asp, and Glu-680/Lys. The Protobothrops sequence lacks asparagine-133, which is present in the other three. Each of the Okinawan species has accumulated several point mutations: Protobothrops (Phe-73, Val-248, Ser-272, Leu-304, Thr-324, Asp-485, and Ovophis (Val-73, Ile-144, Thr-176, Thr-220, Thr-396, Val-473, Glu-559, Asn-577).

Additional file 16: Figure S9. Alignment of a partial vespryn transcript with vespryn sequences from elapid and crotalid venoms. The Protobothrops vespryn [AB851949] is most closely related to that from Lachesis, which also displays a four-residue gap from positions $25-28$. Only three of the first 70 residues differ between these two toxins. The three crotalid vespryns are all 28-32 residues longer at the $\mathrm{N}$-terminus than the two corresponding toxins from Ophiophagus hannah and Pseudechis australis venoms [223].

\section{Competing interests}

The authors declare that they have no competing interests.

\section{Authors' contributions}

This project was conceived and planned by SDA and ASM. All authors participated in data collection. KT obtained, maintained and furnished the snakes. SDA and YW created the CDNA library. MCR performed pilot mass spectrometric data analyses, in addition to processing all of the mass spectrometry samples. AVB designed and revised the mass spectrometric techniques, wrote scripts to extract and process data, and summarized peptidyl data for subsequent comparisons. ASM processed transcriptomic and proteomic data, devised measures of peptide abundance, and performed statistical analyses. SDA reviewed the toxinological literature and analyzed transcriptomic and proteomic data in relation to venom chemistry. SDA and ASM wrote the manuscript. All authors read and approved the final manuscript.

\section{Acknowledgments}

We thank Man-Yin Tin for assistance with sample processing in the laboratory, and the staff at OIST's sequencing center for sequencing the samples. We are grateful for Robert Sinclair's insights regarding challenging sequence alignments. We also thank two anonymous reviewers, whose work was the most painstakingly thorough that any of us have ever seen. Their efforts greatly strengthened and improved the manuscript. Funding for this work was provided to ASM by the Okinawa Institute of Science and Technology.

\section{Author details}

'Okinawa Institute of Science and Technology, Tancha 1919-1, Onna-son, Kunigami-gun, Okinawa-ken 904-0412, Japan. ${ }^{2}$ Okinawa Prefectural Institute of Health and Environment, 2085 Ozato, Ozato Nanjo-shi, Okinawa-ken 901-1202, Japan

Received: 16 February 2013 Accepted: 26 October 2013 Published: 14 November 2013

\section{References}

1. Aird SD: Ophidian envenomation strategies and the role of purines. Toxicon 2002, 40(4):335-393.

2. Mackessy SP: Evolutionary trends in venom composition in the western rattlesnakes (Crotalus viridis sensu lato): toxicity vs. tenderizers. Toxicon 2010, 55(8):1463-1474.

3. Thomas RG, Pough FH: The effect of rattlesnake venom on digestion of prey. Toxicon 1979, 17(3):221-228.

4. Kardong KV: Evolutionary patterns in advanced snakes. American Zoologist 1980, 20(1):269-282.

5. McCue MD: Prey envenomation does not improve digestive performance in western diamondback rattlesnakes (Crotalus atrox). J Exp Zool A Ecol Genet Physiol 2007, 307(10):568-577.

6. Chu CW, Tsai TS, Tsai IH, Lin YS, Tu MC: Prey envenomation does not improve digestive performance in Taiwanese pit vipers (Trimeresurus gracilis and T. stejnegeri stejnegeri). Comp Biochem Physiol A Mol Integr Physiol 2009, 152:579-585.

7. Minton SA Jr: A note on the venom of an aged rattlesnake. Toxicon 1975, 13:73-74.

8. Glenn JL, Straight R: The midget faded rattlesnake (Crotalus viridis concolor) venom: lethal toxicity and individual variability. Toxicon 1977, 15(2):129-133.

9. Glenn JL, Straight R: Mojave rattlesnake Crotalus scutulatus scutulatus venom variation in toxicity with geographical origin. Toxicon 1978, 16(1):81-84.

10. Mackessy SP: Venom ontogeny in the Pacific rattlesnakes Crotalus viridis helleri and C. v. oreganus. Copeia 1988, 1988:92-101.

11. Mackessy SP, Sixberry NM, Heyborne WH, Fritts T: Venom of the Brown Treesnake, Boiga irregularis: ontogenetic shifts and taxa-specific toxicity. Toxicon 2006, 47(5):537-548.

12. Alape-Giron A, Sanz L, Escolano J, Flores-Diaz M, Madrigal M, Sasa M, Calvete JJ: Snake venomics of the lancehead pitviper Bothrops asper: geographic, individual, and ontogenetic variations. J Proteome Res 2008, 7(8):3556-3571.

13. Zelanis A, Tashima AK, Pinto AF, Leme AF, Stuginski DR, Furtado MF, Sherman NE, Ho PL, Fox JW, Serrano SM: Bothrops jararaca venom proteome rearrangement upon neonate to adult transition. Proteomics 2011, 11(21):4218-4228.

14. Calvete JJ, Marcinkiewicz C, Sanz L: Snake venomics of Bitis gabonica gabonica. Protein family composition, subunit organization of venom toxins, and characterization of dimeric disintegrins bitisgabonin-1 and bitisgabonin-2. J Proteome Res 2007, 6(1):326-336.

15. Sanz L, Escolano J, Ferretti M, Biscoglio MJ, Rivera E, Crescenti EJ, Angulo Y Lomonte B, Gutierrez JM, Calvete JJ: Snake venomics of the South and Central American Bushmasters. Comparison of the toxin composition of Lachesis muta gathered from proteomic versus transcriptomic analysis. J Proteomics 2007, 71(1):46-60.

16. Wagstaff SC, Sanz L, Juarez P, Harrison RA, Calvete JJ: Combined snake venomics and venom gland transcriptomic analysis of the ocellated carpet viper, Echis ocellatus. J Proteomics 2009, 71(6):609-623.

17. Rodrigues RS, Boldrini-Franca J, Fonseca FP, de la Torre P, Henrique-Silva F, Sanz L, Calvete JJ, Rodrigues VM: Combined snake venomics and venom gland transcriptomic analysis of Bothropoides pauloensis. $J$ Proteomics 2012, 75(9):2707-2720.

18. Menin L, Perchuc A, Favreau P, Perret F, Michalet S, Schoni R, Wilmer M, Stocklin R: High throughput screening of bradykinin-potentiating peptides in Bothrops moojeni snake venom using precursor ion mass spectrometry. Toxicon 2008, 51(7):1288-1302

19. Correa-Netto C, Junqueira-de-Azevedo Ide L, Silva DA, Ho PL, Leitao-deAraujo M, Alves ML, Sanz L, Foguel D, Zingali RB, Calvete JJ: Snake venomics and venom gland transcriptomic analysis of Brazilian coral snakes, Micrurus altirostris and M. corallinus. J Proteomics 2011, 74(9):1795-1809 
20. Mori A, Toda M: Feeding Characteristics of a Japanese Pitviper, Ovophis okinavensis, on Okinawa Island: Seasonally Biased but Ontogenetically Stable Exploitation on Small Frogs. Current Herpetology 2011, 30(1):41-52

21. Kadota Y: Is Ovophis okinavensis active only in the cool season? Temporal foraging pattern of a subtropical pit viper in Okinawa, Japan. Zoological Studies 2011, 50(3):269-275.

22. Klauber LM: Rattlesnakes: Their Habits, Life Histories, and Influence on Mankind. 2nd edition. Berkeley: University of California Press; 1972.

23. Mushinsky HR: Foraging ecology. In Snakes Ecology and Evolutionary Biology. Edited by Seigel RA, Collins JT, Novak SS. New York: MacMillan Publishing Company; 1987:302-334.

24. Campbell JA, Lamar WW: The Venomous Reptiles of Latin America. Ithaca, New York: Comstock Publishing Associates, Cornell University Press; 1989.

25. Greene HW: Snakes. The Evolution of Mystery in Nature. Berkeley: University of California Press; 1997.

26. Daltry JC, Wüster W, Thorpe RS: Intraspecific variation in the feeding ecology of the crotaline snake Calloselasma rhodostoma in Southeast Asia. J Herpetol 1998, 32(2):198-205.

27. Martins M, Marques OAV, Sazima I: Ecological and phylogenetic correlates of feeding habits in Neotropical pitvipers of the Genus Bothrops. In Biology of the Vipers. Edited by Schuett GW, Höggren M, Douglas ME, Greene HW. Utah: Eagle Mountain Publishing; 2002:307-328.

28. Shine $R$, Wall $M$ : Why is intraspecific niche partitioning more common in snakes than in lizards? In Lizard Ecology. Edited by Reilly SM, McBrayer LB, Miles DB. Cambridge: Cambridge University Press; 2007:173-208.

29. Lin CF, Tu MC: Food Habits of the Taiwanese Mountain Pitviper, Trimeresurus gracilis. Zoological Studies 2008, 47(6):697-703.

30. Nishimura M, Araki Y, Ueda H, Kawashima Y: Frequencies of prey items of habu, Trimeresurus flavoviridis (Viperidae), in the Okinawa Islands. Snake 1991, 23:81-83.

31. Aird SD: Taxonomic distribution and quantitative analysis of free purine and pyrimidine nucleosides in snake venoms. Comp Biochem Physio/ B Biochem Mol Biol 2005, 140(1):109-126.

32. Durban J, Juarez P, Angulo Y, Lomonte B, Flores-Diaz M, Alape-Giron A, Sasa M, Sanz L, Gutierrez JM, Dopazo J, et al: Profiling the venom gland transcriptomes of Costa Rican snakes by 454 pyrosequencing. BMC Genomics 2011, 12:259-274.

33. Fox JW, Serrano SM: Structural considerations of the snake venom metalloproteinases, key members of the M12 reprolysin family of metalloproteinases. Toxicon 2005, 45(8):969-985

34. Fujimura Y, Ikeda Y, Miura S, Yoshida E, Shima H, Nishida S, Suzuki M, Titani K, Taniuchi Y, Kawasaki T: Isolation and characterization of jararaca GPIb-BP, a snake venom antagonist specific to platelet glycoprotein Ib. Thromb Haemost 1995, 74(2):743-750.

35. Swenson S, Costa F, Minea R, Sherwin RP, Ernst W, Fujii G, Yang D, Markland FS Jr: Intravenous liposomal delivery of the snake venom disintegrin contortrostatin limits breast cancer progression. Mol Cancer Ther 2004, 3(4):499-511.

36. Giron ME, Rodriguez-Acosta A, Salazar AM, Sanchez EE, Galan J, Ibarra C, Guerrero B: Isolation and characterization of two new non-hemorrhagic metalloproteinases with fibrinogenolytic activity from the mapanare (Bothrops colombiensis) venom. Arch Toxicol 2013, 87:197-208.

37. Wei JF, Mo YZ, Qiao LY, Wei XL, Chen HQ, Xie H, Fu YL, Wang WY, Xiong $\mathrm{YL}, \mathrm{He} \mathrm{SH}$ : Potent histamine-releasing activity of atrahagin, a novel snake venom metalloproteinase. Int J Biochem Cell Biol 2005, 38:510-520.

38. Kini RM, Evans HJ: Inhibition of platelet aggregation by a fibrinogenase from Naja nigricollis venom is independent of fibrinogen degradation. Biochim Biophys Acta 1991, 1095(2):117-121.

39. Ito $M$, Hamako J, Sakurai $Y$, Matsumoto M, Fujimura Y, Suzuki M, Hashimoto K, Titani K, Matsui T: Complete amino acid sequence of kaouthiagin, a novel cobra venom metalloproteinase with two disintegrin-like sequences. Biochemistry 2001, 40(14):4503-4511.

40. Kamiguti AS, Gallagher P, Marcinkiewicz C, Theakston RD, Zuzel M, Fox JW: Identification of sites in the cysteine-rich domain of the class P-III snake venom metalloproteinases responsible for inhibition of platelet function. FEBS Lett 2003, 549(1-3):129-134.

41. Hsu CC, Wu WB, Huang TF: A snake venom metalloproteinase, kistomin, cleaves platelet glycoprotein VI and impairs platelet functions. J Thromb Haemost 2008, 6(9):1578-1585.
42. Sugiki M, Maruyama M, Yoshida E, Mihara H, Kamiguti AS, Theakston DG: Enhancement of plasma fibrinolysis in vitro by jararhagin, the main haemorrhagic metalloproteinase in Bothrops jararaca venom. Toxicon 1995, 33(12):1605-1617.

43. Ho PL, Serrano SM, Chudzinski-Tavassi AM: Moura da Silva AM, Mentele R, Caldas C, Oliva ML, Batista IF, Oliveira ML: Angiostatin-like molecules are generated by snake venom metalloproteinases. Biochem Biophys Res Commun 2002, 294(4):879-885.

44. Kumar RV, Gowda CD, Shivaprasad HV, Siddesha JM, Sharath BK, Vishwanath BS: Purification and characterization of 'Trimarin' a hemorrhagic metalloprotease with factor Xa-like Activity, from Trimeresurus malabaricus snake venom. Thromb Res 2010, 126(5):e356-e364.

45. Takeya H, Oda K, Miyata T, Omori-Satoh T, Iwanaga S: The complete amino acid sequence of the high molecular mass hemorrhagic protein HR1B isolated from the venom of Trimeresurus flavoviridis. J Biol Chem 1990 265(27):16068-16073

46. Kishimoto M, Takahashi T: Molecular cloning of HR1a and HR1b, high molecular hemorrhagic factors, from Trimeresurus flavoviridis venom Toxicon 2002, 40(9):1369-1375.

47. Chijiwa T, Hamai S, Tsubouchi S, Ogawa T, Deshimaru M, Oda-Ueda N Hattori S, Kihara H, Tsunasawa S, Ohno M: Interisland mutation of a novel phospholipase A2 from Trimeresurus flavoviridis venom and evolution of Crotalinae group II phospholipases A2. J Mol Evol 2003, 57(5):546-554.

48. Kosugi T, Ariga Y, Nakamura M, Kinjo K: Purification and some chemical properties of thrombin-like enzyme from Trimeresurus flavoviridis venom. Thromb Haemost 1986, 55(1):24-30.

49. Kinjoh K, Kosugi T, Nakamura M, Hanashiro K, Sunagawa M, Tokeshi $Y$, Eguchi Y: Habutobin splits the Arg16-Gly17 bond in the A alpha chain of rabbit fibrinogen. Thromb Haemost 1997, 77(6):1127-1128.

50. Sunagawa M, Nakamura M, Kosugi T: Cloning of habutobin CDNA and antithrombotic activity of recombinant protein. Biochem Biophys Res Commun 2007, 362(4):899-904.

51. Nejime T, Kinjoh K, Nakamura M, Hanashiro K, Sunagawa M, Equchi Y, Kosugi T: Habutobin recognizes $\operatorname{Thr}(7)$ in the sequence of fibrinopeptide A of rabbit fibrinogen. Toxicon 2000, 38(8):1029-1041.

52. Oyama $\mathrm{E}$, Takahashi $\mathrm{H}$ : Amino acid sequence of a thrombin like enzyme, elegaxobin, from the venom of Trimeresurus elegans (Sakishima-habu). Toxicon 2002, 40(7):959-970.

53. Oyama $\mathrm{E}$, Takahashi $\mathrm{H}$ : Amino acid sequence of a thrombin like enzyme, elegaxobin II, from the venom of Trimeresurus elegans (Sakishima-Habu). Toxicon 2004, 44(7):711-721.

54. Shieh TC, Kawabata S, Kihara H, Ohno M, Iwanaga S: Amino acid sequence of a coagulant enzyme, flavoxobin, from Trimeresurus flavoviridis venom. J Biochem (Tokyo) 1988, 103(4):596-605.

55. Shieh TC, Tanaka S, Kihara H, Ohno M, Makisumi S: Purification and characterization of a coagulant enzyme from Trimeresurus flavoviridis venom. J Biochem (Tokyo) 1985, 98(3):713-721

56. Yamamoto C, Tsuru D, Oda-Ueda N, Ohno M, Hattori S, Kim ST: Flavoxobin, a serine protease from Trimeresurus flavoviridis (habu snake) venom, independently cleaves Arg726-Ser727 of human C3 and acts as a novel, heterologous C3 convertase. Immunology 2002, 107(1):111-117.

57. Tatematsu R, Komori Y, Nikai T: A new thrombin-like enzyme, flavoviridiobin from the venom of Trimeresurus flavoviridis (habu). J Nat Toxins 2000, 9(4):327-339.

58. Castro HC, Rodrigues CR: Current status of thrombin-like enzymes. Toxin Reviews 2006, 25:291-318.

59. Wu J, Jin Y, Zhong S, Chen R, Zhu S, Wang W, Lu Q, Xiong Y: A unique group of inactive serine protease homologues from snake venom. Toxicon 2008, 52(2):277-284.

60. Wang YM, Parmelee J, Guo YW, Tsai IH: Absence of phospholipase A(2) in most Crotalus horridus venom due to translation blockage: comparison with Crotalus horridus atricaudatus venom. Toxicon 2010, 56(1):93-100.

61. Yamazaki Y, Koike H, Sugiyama Y, Motoyoshi K, Wada T, Hishinuma S, Mita M, Morita T: Cloning and characterization of novel snake venom proteins that block smooth muscle contraction. Eur J Biochem 2002, 269(11):2708-2715.

62. Rokyta DR, Wray KP, Lemmon AR, Lemmon EM, Caudle SB: A high-throughput venom-gland transcriptome for the Eastern Diamondback Rattlesnake (Crotalus adamanteus) and evidence for pervasive positive selection across toxin classes. Toxicon 2011 57(5):657-671. 
63. Hutchinson DA, Mori A, Savitzky AH, Burghardt GM, Wu X, Meinwald J, Schroeder FC: Dietary sequestration of defensive steroids in nuchal glands of the Asian snake Rhabdophis tigrinus. Proc Natl Acad Sci U S A 2007, 104(7):2265-2270.

64. Peichoto ME, Mackessy SP, Teibler P, Tavares FL, Burckhardt PL, Breno MC, Acosta O, Santoro ML: Purification and characterization of a cysteine-rich secretory protein from Philodryas patagoniensis snake venom. Comp Biochem Physiol C Toxicol Pharmacol 2009, 150(1):79-84.

65. Siigur E, Neuman T, Jarve V, Tara A, Siigur J: Isolation and characterization of nerve growth factor from Vipera lebetina (snake) venom. Comp Biochem Physiol B 1985, 81(1):211-215.

66. Guo LY, Zhu JF, Wu XF, Zhou YC: Cloning of a cDNA encoding a nerve growth factor precursor from the Agkistrodon halys Pallas. Toxicon 1999, 37(3):465-470.

67. Kostiza T, Dahinden CA, Rihs S, Otten U, Meier J: Nerve growth factor from the venom of the Chinese cobra Naja naja atra: purification and description of non-neuronal activities. Toxicon 1995, 33(10):1249-1261.

68. Kostiza T, Meier J: Nerve growth factors from snake venoms: chemical properties, mode of action and biological significance. Toxicon 1996, 34(7):787-806.

69. Orenstein NS, Dvorak HF, Blanchard MH, Young M: Nerve growth factor: a protease that can activate plasminogen. Proc Natl Acad Sci U S A 1978, 75(11):5497-5500.

70. Young RJ, Sweeney K: Adenylation and ADP-ribosylation in the mouse 1-cell embryo. J Embryol Exp Morphol 1979, 49:139-152.

71. Clemetson KJ, Morita T, Kini RM: Classification and nomenclature of snake venom C-type lectins and related proteins. Toxicon 2009, 54(1):83.

72. Clemetson KJ: Snaclecs (snake C-type lectins) that inhibit or activate platelets by binding to receptors. Toxicon 2010, 56(7):1236-1246.

73. Morita T: Structures and functions of snake venom CLPs (C-type lectinlike proteins) with anticoagulant-, procoagulant-, and plateletmodulating activities. Toxicon 2005, 45(8):1099-1114

74. Taniuchi $Y$, Kawasaki T, Fujimura Y: The high molecular mass, glycoprotein lb-binding protein flavocetin-A induces only small platelet aggregates in vitro. Thromb Res 2000, 97(2):69-75

75. Taniuchi Y, Kawasaki T, Fujimura Y, Suzuki M, Titani K, Sakai Y, Kaku S, Hisamichi N, Satoh N, Takenaka T, et al: Flavocetin-A and -B, two high molecular mass glycoprotein $\mathrm{lb}$ binding proteins with high affinity purified from Trimeresurus flavoviridis venom, inhibit platelet aggregation at high shear stress. Biochim Biophys Acta 1995, 1244(2-3):331-338.

76. Shin Y, Okuyama I, Hasegawa J, Morita T: Molecular cloning of glycoprotein Ib-binding protein, flavocetin-A, which inhibits platelet aggregation. Thromb Res 2000, 99(3):239-247.

77. Atoda H, Ishikawa M, Yoshihara E, Sekiya F, Morita T: Blood coagulation factor IX-binding protein from the venom of Trimeresurus flavoviridis: purification and characterization. J Biochem 1995, 118(5):965-973.

78. Higuchi S, Murayama N, Saguchi K, Ohi H, Fujita Y, Camargo AC, Ogawa T, Deshimaru M, Ohno M: Bradykinin-potentiating peptides and C-type natriuretic peptides from snake venom. Immunopharmacology 1999 44(1-2):129-135

79. Cintra AC, Vieira CA, Giglio JR: Primary structure and biological activity of bradykinin potentiating peptides from Bothrops insularis snake venom. J Protein Chem 1990, 9(2):221-227.

80. lanzer D, Konno K, Marques-Porto R, Vieira Portaro FC, Stocklin R: Martins de Camargo AC, Pimenta DC: Identification of five new bradykinin potentiating peptides (BPPs) from Bothrops jararaca crude venom by using electrospray ionization tandem mass spectrometry after a two-step liquid chromatography. Peptides 2004, 25(7):1085-1092.

81. Kato H, Suzuki T, Okada K, Kimura T, Sakakibara S: Structure of potentiator A, one of the five bradykinin potentiating peptides from the venom of Agkistrodon halys blomhoffii. Experientia 1973, 29(5):574-575.

82. Chi CW, Wang SZ, Xu LG, Wang MY, Lo SS, Huang WD: Structure-function studies on the bradykinin potentiating peptide from Chinese snake venom (Agkistrodon halys Pallas). Peptides 1985, 6(Suppl 3):339-342.

83. Ferreira SH, Bartelt DC, Greene $\sqcup$ : Isolation of bradykinin-potentiating peptides from Bothrops jararaca venom. Biochemistry 1970, 9(13):2583-2593.

84. Ianzer D, Santos RA, Etelvino GM, Xavier CH, de Almeida SJ, Mendes EP, Machado LT, Prezoto BC, Dive V, de Camargo AC: Do the cardiovascular effects of angiotensin-converting enzyme (ACE) I involve ACE-independent mechanisms? new insights from proline-rich peptides of Bothrops jararaca. J Pharmacol Exp Ther 2007, 322(2):795-805.
85. Ianzer D, Xavier CH, Fraga FC, Lautner RQ, Guerreiro JR, Machado LT, Mendes EP, de Camargo AC, Santos RA: BPP-5a produces a potent and long-lasting NO-dependent antihypertensive effect. Therapeutic advances in cardiovascular disease 2011, 5(6):281-295.

86. Guerreiro JR, Lameu C, Oliveira EF, Klitzke CF, Melo RL, Linares E, Augusto O, Fox JW, Lebrun I, Serrano SM, et al: Argininosuccinate synthetase is a functional target for a snake venom anti-hypertensive peptide: role in arginine and nitric oxide production. J Biol Chem 2009, 284(30):20022-20033.

87. Tashima AK, Zelanis A, Kitano ES, lanzer D, Melo RL, Rioli V, Sant'anna SS, Schenberg AC, Camargo AC, Serrano SM: Peptidomics of three Bothrops snake venoms: insights into the molecular diversification of proteomes and peptidomes. Mol Cell Proteomics 2012, 11(11):1245-1262.

88. Ferreira LA, Henriques OB, Lebrun I, Batista MB, Prezoto BC, Andreoni AS, Zelnik R, Habermehl G: A new bradykinin-potentiating peptide (peptide P) isolated from the venom of Bothrops jararacussu (jararacucu tapete, urutu dourado). Toxicon 1992, 30(1):33-40.

89. Ferreira LAF, Auer $H$, Haslinger E, Fedele C, Habermehl GG: Spatial structures of the bradykinin potentiating peptide $\mathrm{F}$ from Agkistrodon piscivorus piscivoris venom. Toxicon 1999, 37(4):661-676.

90. Doery HM, Pearson JE: Phospholipase B in snake venoms and bee venom. Biochem J 1964, 92(3):599-602.

91. Bernheimer AW, Linder R, Weinstein SA, Kim KS: Isolation and characterization of a phospholipase B from venom of Collett's snake, Pseudechis colletti. Toxicon 1987, 25(5):547-554.

92. Chatrath ST, Chapeaurouge A, Lin Q, Lim TK, Dunstan N, Mirtschin P, Kumar PP, Kini RM: Identification of novel proteins from the venom of a cryptic Snake Drysdalia coronoides by a combined transcriptomics and proteomics approach. J Proteome Res 2011, 10(2):739-750.

93. Feola M, Simoni J, Tran R, Lox CD, Canizaro PC: Toxic factors in the red blood cell membrane. J Trauma 1989, 29(8):1065-1075.

94. Kinoshita T, Inoue K, Okada M, Akiyama Y: Release of phospholipids from liposomal model membrane damaged by antibody and complement. J Immunol 1977, 119(1):73-76

95. Ferrara N, Gerber HP, LeCouter J: The biology of VEGF and its receptors. Nat Med 2003, 9(6):669-676.

96. Takahashi $H$, Hattori S, Iwamatsu A, Takizawa H, Shibuya M: A novel snake venom vascular endothelial growth factor (VEGF) predominantly induces vascular permeability through preferential signaling via VEGF receptor-1. J Biol Chem 2004, 279(44):46304-46314.

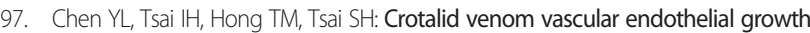
factors has preferential affinity for VEGFR-1. Characterization of Protobothrops mucrosquamatus venom VEGF. Thromb Haemost 2005, 93(2):331-338.

98. Yamazaki Y, Matsunaga Y, Tokunaga Y, Obayashi S, Saito M, Morita T: Snake venom Vascular Endothelial Growth Factors (VEGF-Fs) exclusively vary their structures and functions among species. J Biol Chem 2009, 284(15):9885-9891

99. Ku DD, Zaleski JK, Liu S, Brock TA: Vascular endothelial growth factor induces EDRF-dependent relaxation in coronary arteries. Am J Physiol 1993, 265(2 Pt 2):H586-H592.

100. Weis SM, Cheresh DA: Pathophysiological consequences of VEGF-induced vascular permeability. Nature 2005, 437(7058):497-504

101. Yang R, Thomas GR, Bunting S, Ko A, Ferrara N, Keyt B, Ross J, Jin H: Effects of vascular endothelial growth factor on hemodynamics and cardiac performance. J Cardiovasc Pharmacol 1996, 27(6):838-844.

102. Tokunaga Y, Yamazaki Y, Morita T: Identification and localization of heparin-binding region of snake venom VEGF and its blocking of VEGF-A165. Pathophysiol Haemost Thromb 2005, 34(4-5):194-196.

103. Yamazaki Y, Nakano Y, Imamura T, Morita T: Augmentation of vascular permeability of VEGF is enhanced by KDR-binding proteins. Biochem Biophys Res Commun 2007, 355(3):693-699.

104. Iwanaga S, Suzuki T: Enzymes in snake venoms. In Snake Venoms, vol. 52. Edited by Lee C-Y. Berlin: Springer-Verlag; 1979:61-158.

105. Tan NH, Ponnudurai G: Comparative study of the enzymatic, hemorrhagic, procoagulant and anticoagulant activities of some animal venoms. Comp Biochem Physiol C 1992, 103(2):299-302.

106. Tan NH, Ponnudurai G: A comparative study of the biological properties of venoms of some old world vipers (Subfamily Viperinae). Int J Biochem 1992, 24(2):331-336.

107. Jorge da Silva N Jr, Aird SD: Prey specificity, comparative lethality and compositional differences of coral snake venoms. Comp Biochem Physio/ C Toxicol Pharmacol 2001, 128(3):425-456. 
108. Heppel LA, Hilmoe RJ: Purification and properties of 5'-nucleotidase. J Biol Chem 1951, 188:665-676.

109. Mizuno Y, Ikehara M, Ueda T, Nomura A, Ohtsuka E, Ishikawa F, Kanai Y: Interactions between synthetic nucleotide analogs and snake venom 5'-nucleotidase. Chem Pharm Bull 1961, 9:338-340

110. Sulkowski E, Bjork W, Laskowski M Sr: A specific and nonspecific alkaline monophosphatase in the venom of Bothrops atrox and their occurrence in the purified venom phosphodiesterase. J Biol Chem 1963, 238:2477-2486.

111. Gartner TK, Ogilvie ML: Isolation and characterization of three Ca2 + -dependent beta-galactoside-specific lectins from snake venoms. Biochem J 1984, 224(1):301-307.

112. Gartner TK, Stocker K, Williams DC: Thrombolectin: a lectin isolated from Bothrops atrox venom. FEBS Lett 1980, 117(1):13-16

113. Helmbold W, Fehres J, Prokop O, Uhlenbruck G, Janssen E: B and T lymphocyte mitogenic properties in a snake venom. Biomed Biochim Acta 1986, 45(4):459-466

114. Helmbold W, Prokop O, Uhlenbruck G, Bohmer G, Lutticken R: Snake venom lectins: a new group of $\mathrm{T}$ - and B-cell mitogenic anti-galactans. Biomed Biochim Acta 1985, 44(11-12):K91-K96.

115. Mastro AM, Hurley DJ, Winning RK, Filipowski R, Ogilvie ML, Gartner TK: Mitogenic activity of snake venom lectins. Cell Tissue Kinet 1986, 19(5):557-566

116. Fry BG, Wuster W: Assembling an arsenal: origin and evolution of the snake venom proteome inferred from phylogenetic analysis of toxin sequences. Mol Biol Evol 2004, 21(5):870-883.

117. Ogawa T, Chijiwa T, Oda-Ueda N, Ohno M: Molecular diversity and accelerated evolution of C-type lectin-like proteins from snake venom. Toxicon 2005, 45(1):1-14.

118. Beyer EC, Tokuyasu KT, Barondes SH: Localization of an endogenous lectin in chicken liver, intestine, and pancreas. J Cell Biol 1979, 82(2):565-571.

119. Ogilvie ML, Dockter ME, Wenz L, Gartner TK: Isolation and characterization of lactose-binding lectins from the venoms of the snakes Lachesis muta and Dendroaspis jamesonii. J Biochem (Tokyo) 1986, 100(6):1425-1431.

120. Lomonte B, Rojas G, Gutierrez JM, Ramirez G: Isolation of a galactose-binding lectin from the venom of the snake Bothrops godmani (Godmann's pit viper). Toxicon 1990, 28(1):75-81.

121. Danziger RS: Aminopeptidase $\mathrm{N}$ in arterial hypertension. Heart Fail Rev 2008, 13(3):293-298

122. Mitsui T, Nomura S, Itakura A, Mizutani S: Role of aminopeptidases in the blood pressure regulation. Biol Pharm Bull 2004, 27(6):768-771.

123. Bodineau L, Frugiere A, Marc Y, Claperon C, Llorens-Cortes C: Aminopeptidase A inhibitors as centrally acting antihypertensive agents. Heart Fail Rev 2008, 13(3):311-319

124. Mizutani S, Taira H, Kurauchi O, Ito $Y$, Imaizumi H, Furuhashi M, Narita O, Tomoda Y: Effect of microsomal leucine aminopeptidase from human placenta (microsomal P-LAP) on pressor response to infused angiotensin II (A-II) in rat. Exp Clin Endocrinol 1987, 90(2):206-212.

125. Mizutani S, Okano K, Hasegawa E, Sakura H, Oya M, Yamada M: Human placental leucine aminopeptidase (P-LAP) as a hypotensive agent. Experientia 1982, 38(7):821-822.

126. Ahmad S, Ward PE: Role of aminopeptidase activity in the regulation of the pressor activity of circulating angiotensins. J Pharmacol Exp Ther 1990, 252(2):643-650.

127. Ogawa Y, Murayama N, Fujita Y, Yanoshita R: Characterization and cDNA cloning of aminopeptidase A from the venom of Gloydius blomhoffi brevicaudus. Toxicon 2007, 49(8):1172-1181.

128. Tu AT, Toom PM: The presence of a L-leucyl-beta-napthylamide hydrolyzing enzyme in snake venoms. Experientia 1967, 23(6):439-440

129. Ogawa Y, Mamura Y, Murayama N, Yanoshita R: Characterization and cDNA cloning of dipeptidyl peptidase IV from the venom of Gloydius blomhoffi brevicaudus. Comp Biochem Physiol B Biochem Mol Biol 2006, 145(1):35-42.

130. Ogawa Y, Kanai-Azuma M, Akimoto Y, Kawakami H, Yanoshita R: Exosome-like vesicles in Gloydius blomhoffii blomhoffii venom. Toxicon 2008, 51(6):984-993.

131. Aird SD: A quantitative assessment of variation in venom constituents within and between three nominal rattlesnake subspecies. Toxicon 1985, 23(6):1000-1004.

132. Aird SD: Chromatographic behavior of Bothrops erythromelas phospholipase and other venom constituents on Superdex 75 Prep Biochem Biotechnol 2004, 34(4):345-364.
133. Ogawa Y, Kanai-Azuma M, Akimoto Y, Kawakami H, Yanoshita R: Exosome-like vesicles with dipeptidyl peptidase IV in human saliva. Biol Pharm Bull 2008, 31(6):1059-1062.

134. Aird SD: Snake venom dipeptidyl peptidase IV: taxonomic distribution and quantitative variation. Comp Biochem Physiol B Biochem Mol Biol 2008, 150(2):222-228.

135. Calvete JJ, Fasoli E, Sanz L, Boschetti E, Righetti PG: Exploring the venom proteome of the western diamondback rattlesnake, Crotalus atrox, via snake venomics and combinatorial peptide ligand library approaches. J Proteome Res 2009, 8(6):3055-3067.

136. Takeya H, Arakawa M, Miyata T, Iwanaga S, Omori-Satoh T: Primary structure of $\mathrm{H} 2$-proteinase, a non-hemorrhagic metalloproteinase, isolated from the venom of the habu snake, Trimeresurus flavoviridis. J Biochem (Tokyo) 1989, 106(1):151-157.

137. Randolph A, Chamberlain SH, Chu HL, Retzios AD, Markland FS Jr, Masiarz FR: Amino acid sequence of fibrolase, a direct-acting fibrinolytic enzyme from Agkistrodon contortrix contortrix venom. Protein Sci 1992, 1(5):590-600.

138. Terada S, Hori J, Fujimura S, Kimoto E: Purification and amino acid sequence of brevilysin L6, a non-hemorrhagic metalloprotease from Agkistrodon halys brevicaudus venom. J Biochem (Tokyo) 1999, 125(1):64-69.

139. Aird SD, Kaiser II, Lewis RV, Kruggel WG: Rattlesnake presynaptic neurotoxins: primary structure and evolutionary origin of the acidic subunit. Biochemistry 1985, 24(25):7054-7058.

140. Aird SD, Yates JR 3rd, Martino PA, Shabanowitz J, Hunt DF, Kaiser II: The amino acid sequence of the acidic subunit B-chain of crotoxin. Biochim Biophys Acta 1990, 1040(2):217-224.

141. Pawlak J, Manjunatha Kini R: Snake venom glutaminyl cyclase. Toxicon 2006, 48(3):278-286.

142. Tu AT, Hendon RR: Characterization of lizard venom hyaluronidase and evidence for its action as a spreading factor. Comp Biochem Physiol $B$ 1983, 76(2):377-383.

143. Girish KS, Mohanakumari HP, Nagaraju S, Vishwanath BS, Kemparaju K: Hyaluronidase and protease activities from Indian snake venoms: neutralization by Mimosa pudica root extract. Fitoterapia 2004 75(3-4):378-380.

144. Pahari S, Mackessy SP, Kini RM: The venom gland transcriptome of the Desert Massasauga rattlesnake (Sistrurus catenatus edwardsii): towards an understanding of venom composition among advanced snakes (Superfamily Colubroidea). BMC Mol Biol 2007, 8:115.

145. Nirthanan S, Charpantier E, Gopalakrishnakone P, Gwee MC, Khoo HE, Cheah LS, Bertrand D, Kini RM: Candoxin, a novel toxin from Bungarus candidus, is a reversible antagonist of muscle (alphabetagammadelta) but a poorly reversible antagonist of neuronal alpha 7 nicotinic acetylcholine receptors. J Biol Chem 2002, 277(20):17811-17820.

146. Juarez P, Sanz L, Calvete JJ: Snake venomics: characterization of protein families in Sistrurus barbouri venom by cysteine mapping, N-terminal sequencing, and tandem mass spectrometry analysis. Proteomics 2004 4(2):327-338.

147. Junqueira-de-Azevedo Ide L, Ho PL: A survey of gene expression and diversity in the venom glands of the pitviper snake Bothrops insularis through the generation of expressed sequence tags (ESTs). Gene 2002, 299(1-2):279-291.

148. Kashima S, Roberto PG, Soares AM, Astolfi-Filho S, Pereira JO, Giuliati S, Faria M $\mathrm{Jr}$, Xavier MA, Fontes MR, Giglio JR, et al: Analysis of Bothrops jararacussu venomous gland transcriptome focusing on structural and functional aspects: I-gene expression profile of highly expressed phospholipases A2. Biochimie 2004, 86(3):211-219.

149. Qinghua L, Xiaowei Z, Wei Y, Chenji L, Yijun H, Pengxin Q, Xingwen S, Songnian $\mathrm{H}$, Guangmei $\mathrm{Y}$ : A catalog for transcripts in the venom gland of the Agkistrodon acutus: identification of the toxins potentially involved in coagulopathy. Biochem Biophys Res Commun 2006, 341(2):522-531.

150. Zhang B, Liu Q, Yin W, Zhang X, Huang Y, Luo Y, Qiu P, Su X, Yu J, Hu S, et al: Transcriptome analysis of Deinagkistrodon acutus venomous gland focusing on cellular structure and functional aspects using expressed sequence tags. BMC Genomics 2006, 7:152.

151. Boldrini-França J, Correa-Netto C, Silva MM, Rodrigues RS, De La Torre P, Perez A, Soares AM, Zingali RB, Nogueira RA, Rodrigues VM, et al: Snake venomics and antivenomics of Crotalus durissus subspecies from Brazil assessment of geographic variation and its implication on snakebite management. J Proteomics 2010, 73(9):1758-1776. 
152. Boldrini-França J, Rodrigues RS, Fonseca FP, Menaldo DL, Ferreira FB, Henrique-Silva F, Soares AM, Hamaguchi A, Rodrigues VM, Otaviano AR, et al: Crotalus durissus collilineatus venom gland transcriptome: analysis of gene expression profile. Biochimie 2009, 91(5):586-595.

153. Rokyta DR, Lemmon AR, Margres MJ, Aronow K. The venom-gland transcriptome of the eastern diamondback rattlesnake (Crotalus adamanteus). BMC Genomics 2012, 13:312.

154. Weldon CL, Mackessy SP: Biological and proteomic analysis of venom from the Puerto Rican Racer (Alsophis portoricensis: Dipsadidae). Toxicon 2010, 55(2-3):558-569.

155. Gonçalves JM, Polson A: The electrophoretic analysis of snake venoms. Arch. Biochem 1947, 13:253-259.

156. Cameron DL, Tu AT: Chemical and functional homology of myotoxin a from prairie rattlesnake venom and crotamine from South American rattlesnake venom. Biochim Biophys Acta 1978, 532(1):147-154

157. Engle CM, Becker RR, Bailey T, Bieber AL: Characterization of two myotoxic proteins from venom of Crotalus viridis concolor. J Toxicol -. Toxin Rev 1983, 2(2):267-283

158. Bober MA, Glenn JL, Straight RC, Ownby CL: Detection of myotoxin alphalike proteins in various snake venoms. Toxicon 1988, 26(7):665-673.

159. Samejima Y, Aoki Y, Mebs D: Amino acid sequence of a myotoxin from venom of the eastern diamondback rattlesnake (Crotalus adamanteus). Toxicon 1991, 29(4-5):461-468.

160. Johnson EK, Ownby CL: Isolation of a myotoxin from the venom of Agkistrodon contortrix laticinctus (broad-banded copperhead) and pathogenesis of myonecrosis induced by it in mice. Toxicon 1993, 31(3):243-255.

161. Schenberg S: Geographical pattern of crotamine distribution in the same rattlesnake subspecies. Science 1959, 129:1361-1363.

162. Griffin PR, Aird SD: A new small myotoxin from the venom of the prairie rattlesnake (Crotalus viridis viridis). FEBS Lett 1990, 274(1-2):43-47.

163. Chang CC, Hong SJ, Su MJ: A study on the membrane depolarization of skeletal muscles caused by a scorpion toxin, sea anemone toxin II and crotamine and the interaction between toxins. Br J Pharmacol 1983, 79(3):673-680

164. Chang CC, Tseng KH: Effect of crotamine, a toxin of South American rattlesnake venom, on the sodium channel of murine skeletal muscle. Br J Pharmacol 1978, 63(3):551-559.

165. Tsai MC, IS P, Chang CC: Electrophysiological studies of crotamine on the rat skeletal muscle membrane. Proc Natl Sci Counc Repub China Part B Basic Sci 1981, 5(3):307-313.

166. Utaisincharoen P, Baker B, Tu AT: Binding of myotoxin a to sarcoplasmic

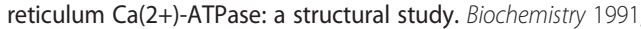
30(33):8211-8216.

167. Hong SJ, Lin WW, Chang CC: Inhibition of the Sodium Channel by SK\&F 96365, an Inhibitor of the Receptor-Operated Calcium Channel, in Mouse Diaphragm. J Biomed Sci 1994, 1(3):172-178

168. Ohkura M, Ide T, Furukawa K, Kawasaki T, Kasai M, Ohizumi Y: Calsequestrin is essential for the Ca2+ release induced by myotoxin alpha in skeletal muscle sarcoplasmic reticulum. Can J Physiol Pharmacol 1995, 73(8):1181-1185.

169. Matavel AC, Ferreira-Alves DL, Beirao PS, Cruz JS: Tension generation and increase in voltage-activated $\mathrm{Na}+$ current by crotamine. Eur J Pharmacol 1998, 348(2-3):167-173.

170. Mancin AC, Soares AM, Andriao-Escarso SH, Faca VM, Greene $\sqcup$, Zuccolotto S, Pela IR, Giglio JR: The analgesic activity of crotamine, a neurotoxin from Crotalus durissus terrificus (South American rattlesnake) venom: a biochemical and pharmacological study. Toxicon 1998, 36(12):1927-1937.

171. Mancin AC, Soares AM, Giglio CA, Andriao-Escarso SH, Vieira CA, Giglio JR: The histamine releasers crotamine, protamine and compound 48/80 activate specific proteases and phospholipases A2. Biochem Mol Biol Int 1997, 42(6):1171-1177

172. Kerkis A, Kerkis I, Radis-Baptista G, Oliveira EB, Vianna-Morgante AM, Pereira LV, Yamane T: Crotamine is a novel cell-penetrating protein from the venom of rattlesnake Crotalus durissus terrificus. Faseb J 2004, 18(12):1407-1409.

173. Oguiura N, Boni-Mitake M, Radis-Baptista G: New view on crotamine, a small basic polypeptide myotoxin from South American rattlesnake venom. Toxicon 2005, 46(4):363-370.

174. Yount NY, Kupferwasser D, Spisni A, Dutz SM, Ramjan ZH, Sharma S, Waring AJ, Yeaman MR: Selective reciprocity in antimicrobial activity versus cytotoxicity of hBD-2 and crotamine. Proc Natl Acad Sci U S A 2009, 106(35):14972-14977.
175. Marcussi S, Santos PR, Menaldo DL, Silveira LB, Santos-Filho NA, Mazzi MV, da Silva SL, Stabeli RG, Antunes LM, Soares AM: Evaluation of the genotoxicity of Crotalus durissus terrificus snake venom and its isolated toxins on human lymphocytes. Mutat Res 2011, 724(1-2):59-63.

176. Oguiura N, Boni-Mitake M, Affonso R, Zhang G: In vitro antibacterial and hemolytic activities of crotamine, a small basic myotoxin from rattlesnake Crotalus durissus. J Antibiot (Tokyo) 2011, 64(4):327-331.

177. O'Keefe MP, Nedelkov D, Bieber AL, Nieman RA: Evidence for isomerization in myotoxin a from the prairie rattlesnake (Crotalus viridis viridis). Toxicon 1996, 34(4):417-434.

178. Nedelkov D, O'Keefe MP, Chapman TL, Bieber AL: The role of Pro20 in the isomerization of myotoxin a from Crotalus viridis viridis: folding and structural characterization of synthetic myotoxin a and its Pro20Gly homolog. Biochem Biophys Res Commun 1997, 241(2):525-529.

179. Marquardt H, Todaro GJ, Twardzik DR: Snake venom Growth Arresting Peptide; 1988. United States Patent 4,774,318.

180. Radis-Baptista G, Kubo T, Oguiura N: Prieto da Silva AR, Hayashi MA, Oliveira EB, Yamane T: Identification of crotasin, a crotamine-related gene of Crotalus durissus terrificus. Toxicon 2004, 43(7):751-759.

181. Radis-Baptista G, Oguiura N, Hayashi MA, Camargo ME, Grego KF, Oliveira $E B$, Yamane T: Nucleotide sequence of crotamine isoform precursors from a single South American rattlesnake (Crotalus durissus terrificus). Toxicon 1999, 37(7):973-984.

182. Oguiura N, Collares MA, Furtado MF, Ferrarezzi H, Suzuki H: Intraspecific variation of the crotamine and crotasin genes in Crotalus durissus rattlesnakes. Gene 2009, 446(1):35-40.

183. Simpson KJ, Ranganathan S, Fisher JA, Janssens PA, Shaw DC, Nicholas KR: The gene for a novel member of the whey acidic protein family encodes three four-disulfide core domains and is asynchronously expressed during lactation. J Biol Chem 2000, 275(30):23074-23081.

184. Tomee JF, Koeter GH, Hiemstra PS, Kauffman HF: Secretory leukoprotease inhibitor: a native antimicrobial protein presenting a new therapeutic option? Thorax 1998, 53(2):114-116

185. Zhu J, Nathan C, Jin W, Sim D, Ashcroft GS, Wahl SM, Lacomis L, Erdjument-Bromage $H$, Tempst $P$, Wright $C D$, et al: Conversion of proepithelin to epithelins: roles of SLPI and elastase in host defense and wound repair. Cell 2002, 111(6):867-878.

186. Torres AM, Wong HY, Desai M, Moochhala S, Kuchel PW, Kini RM: Identification of a novel family of proteins in snake venoms. Purification and structural characterization of nawaprin from Naja nigricollis snake venom. J Biol Chem 2003, 278(41):40097-40104.

187. Clauss A, Lilja H, Lundwall A: A locus on human chromosome 20 contains several genes expressing protease inhibitor domains with homology to whey acidic protein. Biochem J 2002, 368(Pt 1):233-242.

188. Dufton MJ: Proteinase inhibitors and dendrotoxins. Sequence classification, structural prediction and structure/activity. Eur J Biochem 1985, 153(3):647-654

189. Harvey AL, Karlsson E: Protease inhibitor homologues from mamba venoms: facilitation of acetylcholine release and interactions with prejunctional blocking toxins. Br J Pharmacol 1982, 77(1):153-161.

190. Ueda E, Kokubu T, Akutsu H, Yamamura Y: Inhibition of angiotensin I converting enzyme and kininase in rabbit plasma by bradykinin potentiating peptide B (Pyr-Gly-Leu-Pro-Arg-Pro-Lys-Ile-Pro-Pro). Experientia 1971, 27(9):1020-1021

191. Yanoshita R, Kasuga A, Inoue S, Ikeda K, Samejima Y: Blomhotin: a novel peptide with smooth muscle contractile activity identified in the venom of Agkistrodon halys blomhoffii. Toxicon 1999, 37(12):1761-1770.

192. Hayashi MA, Camargo AC: The bradykinin-potentiating peptides from venom gland and brain of Bothrops jararaca contain highly site specific inhibitors of the somatic angiotensin-converting enzyme. Toxicon 2005 , 45(8):1163-1170

193. Robeva A, Politi V, Shannon JD, Bjarnason JB, Fox JW: Synthetic and endogenous inhibitors of snake venom metalloproteinases. Biomed Biochim Acta 1991, 50(4-6):769-773.

194. Joubert FJ, Taljaard N: The complete primary structures of two reduced and S-carboxymethylated angusticeps-type toxins from Dendroaspis angusticeps (green mamba) venom. Biochim Biophys Acta 1980, 623(2):449-456.

195. Adams M: Tissue factor pathway inhibitor: new insights into an old inhibitor. Semin Thromb Hemost 2012, 38(2):129-134.

196. Broze GJ Jr, Girard TJ: Tissue factor pathway inhibitor: structure-function. Front Biosci 2012, 17:262-280. 
197. Maroney SA, Mast AE: Platelet tissue factor pathway inhibitor modulates intravascular coagulation. Thromb Res 2012, 129(Suppl 2):S21-S22.

198. Maroney SA, Ellery PE, Mast AE: Alternatively spliced isoforms of tissue factor pathway inhibitor. Thromb Res 2010, 125(Suppl 1):S52-S56.

199. Mende TJ, Moreno M: A heat stable paraoxonase (O, O-diethyl O-pnitrophenyl phosphate O-p-nitrophenyl hydrolase) from Russell's viper venom. Biochemistry 1975, 14(17):3913-3916.

200. Rajkovic MG, Rumora L, Barisic K: The paraoxonase 1, 2 and 3 in humans. Biochem Med (Zagreb) 2011, 21(2):122-130.

201. Pung YF, Wong PT, Kumar PP, Hodgson WC, Kini RM: Ohanin, a novel protein from king cobra venom, induces hypolocomotion and hyperalgesia in mice. J Biol Chem 2005, 280(13):13137-13147.

202. Junqueira-de-Azevedo IL, Ching AT, Carvalho E, Faria F, Nishiyama MY Jr, Ho PL, Diniz MR: Lachesis muta (Viperidae) CDNAs reveal diverging pit viper molecules and scaffolds typical of cobra (Elapidae) venoms: implications for snake toxin repertoire evolution. Genetics 2006, 173(2):877-889.

203. St Pierre L, Fischer H, Adams DJ, Schenning M, Lavidis N, de Jersey J, Masci PP, Lavin MF: Distinct activities of novel neurotoxins from Australian venomous snakes for nicotinic acetylcholine receptors. Cell Mol Life SC 2007, 64(21):2829-2840.

204. Chen T, Bjourson AJ, Orr DF, Kwok H, Rao P, Ivanyi C, Shaw C: Unmasking venom gland transcriptomes in reptile venoms. Anal Biochem 2002, 311(2):152-156

205. Currier RB, Calvete JJ, Sanz L, Harrison RA, Rowley PD, Wagstaff SC: Unusual stability of messenger RNA in snake venom reveals gene expression dynamics of venom replenishment. PLoS One 2012, 7(8):e41888.

206. Smeds $L$, Kunstner A: ConDeTri-a content dependent read trimmer for Illumina data. PloS one 2011, 6(10):e26314

207. Garber M, Grabherr MG, Guttman M, Trapnell C: Computational methods for transcriptome annotation and quantification using RNA-seq. Nature methods 2011, 8(6):469-477.

208. Grabherr MG, Haas BJ, Yassour M, Levin JZ, Thompson DA, Amit I, Adiconis $X$, Fan L, Raychowdhury $R$, Zeng $Q$, et al: Full-length transcriptome assembly from RNA-Seq data without a reference genome. Nature biotechnology 2011, 29(7):644-652.

209. Li B, Dewey CN: RSEM: accurate transcript quantification from RNA-Seq data with or without a reference genome. BMC bioinformatics 2011, 12:323.

210. Mortazavi A, Williams BA, McCue K, Schaeffer L, Wold B: Mapping and quantifying mammalian transcriptomes by RNA-Seq. Nature methods 2008, 5(7):621-628

211. Ferreira LAF, Mollring T, Lebrun FL, Raida M, Znottka R, Habermehl GG: Structure and effects of a kinin potentiating fraction $F(A p p F)$ isolated from Agkistrodon piscivorus piscivorus venom. Toxicon 1995, 33(10):1313-1319.

212. Ferreira LAF, Galle A, Raida M, Schrader M, Lebrun I, Habermehl G: Isolation: analysis and properties of three bradykinin-potentiating peptides (BPP-II, BPP-III, and BPP-V) from Bothrops neuwiedi venom. J Protein Chem 1998, 17(3):285-289

213. Greene LJ, Ferreira SH, Stewart JM: Bradykinin potentiating factor. Chest 1971, 59(Suppl):9S-10S

214. Higuchi S, Murayama N, Saguchi K, Ohi H, Fujita Y, da Silva NJ Jr, de Siqueira RJ, Lahlou S, Aird SD: A novel peptide from the ACEI/BPP-CNP precursor in the venom of Crotalus durissus collilineatus. Comp Biochem Physiol C Toxicol Pharmacol 2006, 144(2):107-121.

215. Kato H, Suzuki T: Bradykinin-potentiating peptides from the venom of Agkistrodon halys blomhoffii. Isolation of five bradykinin potentiators and the amino acid sequences of two of them, Potentiators B and C. Biochemistry 1971, 10(6):972-980.

216. Komori Y, Sugihara $\mathrm{H}$ : Characterization of a new inhibitor for angiotensin converting enzyme from the venom of Vipera aspis aspis. Int J Biochem 1990, 22(7):767-771.

217. Murayama N, Michel GH, Yanoshita R, Samejima Y, Saguchi K, Ohi H, Fujita $Y$, Higuchi S: cDNA cloning of bradykinin-potentiating peptides-C-type natriuretic peptide precursor, and characterization of the novel peptide Leu3-blomhotin from the venom of Agkistrodon blomhoffi. Eur J Biochem 2000, 267(13):4075-4080.

218. Ondetti MA, Williams NJ, Sabo EF, Pluscec J, Weaver ER, Kocy O: Angiotensin-converting enzyme inhibitors from the venom of Bothrops jararaca. Isolation, elucidation of structure, and synthesis. Biochemistry 1971, 10(22):4033-4039.
219. Politi V, De Luca G, Di Stazio G, Schinina E, Bossa F: A new peptide from Crotalus atrox snake venom. Peptides 1985, 6(Suppl 3):343-346.

220. Soares MR, Oliveira-Carvalho AL, Wermelinger LS, Zingali RB, Ho PL, Junqueira-de-Azevedo Ide L, Diniz MR: Identification of novel bradykininpotentiating peptides and C-type natriuretic peptide from Lachesis muta venom. Toxicon 2005, 46(1):31-38.

221. Wermelinger LS, Dutra DL, Oliveira-Carvalho AL, Soares MR, Bloch C Jr, Zingali RB: Fast analysis of low molecular mass compounds present in snake venom: identification of ten new pyroglutamate-containing peptides. Rapid Commun Mass Spectrom 2005, 19(12):1703-1708.

222. Graham RLJ, Graham C, McClean S, Chen T, O'Rourke M, Hirst D, Theakston $D$, Shaw C: Identification and functional analysis of a novel bradykinin inhibitory peptide in the venoms of New World Crotalinae pit vipers. Biochem Biophys Res Commun 2005, 338(3):1587-1592.

223. St Pierre L, Birrell GW, Earl ST, Wallis TP, Gorman JJ, de Jersey J, Masci PP Lavin MF: Diversity of toxic components from the venom of the evolutionarily distinct black whip snake, Demansia vestigiata. J Proteome Res 2007, 6(8):3093-3107.

doi:10.1186/1471-2164-14-790

Cite this article as: Aird et al:: Quantitative high-throughput profiling of snake venom gland transcriptomes and proteomes (Ovophis okinavensis and Protobothrops flavoviridis). BMC Genomics 2013 14:790.

\section{Submit your next manuscript to BioMed Central and take full advantage of:}

- Convenient online submission

- Thorough peer review

- No space constraints or color figure charges

- Immediate publication on acceptance

- Inclusion in PubMed, CAS, Scopus and Google Scholar

- Research which is freely available for redistribution

Submit your manuscript at www.biomedcentral.com/submit
C Biomed Central 